\title{
Trace metals partitioning among different sedimentary mineral phases and the deposit-feeding polychaete Armandia brevis
}

\author{
Margarita Díaz-de-Alba a , Miguel Angel Huerta-Diaz ${ }^{\text {b,* }}$, Francisco Delgadillo-Hinojosa ${ }^{\text {b }}$, Landis Hare ${ }^{\text {c }}$, \\ M. Dolores Galindo-Riaño ${ }^{\mathrm{a}}$, Arturo Siqueiros-Valencia ${ }^{\mathrm{b}}$ \\ a Department of Analytical Chemistry, Institute of Biomolecules (INBIO), Faculty of Sciences, CEI-MAR, University of Cadiz, Campus Rio S. Pedro, E-11510, Puerto Real, Cadiz, Spain \\ ${ }^{\mathrm{b}}$ Instituto de Investigaciones Oceanológicas, Universidad Autónoma de Baja California, Campus Ensenada, Km. 103 Carr. Tijuana-Ensenada, Ensenada 22800, Baja California, Mexico \\ ' Centre Eau Terre Environnement, 490, rue de la Couronne, Québec, Québec G1K 9A9, Canada
}

\section{H I G H L I G H T S}

- A positive relationship was found between $\mathrm{HCl}$ and pyrite trace metal concentrations

- Incorporation of trace metals into pyrite is a function of their solubility product

- Every year 98 metric tons of Fe are precipitated as pyrite in Ensenada Harbor

- Dredging operations can export as much as $(0.30 \pm 0.56) \times 10^{3}$ metric tons of $\mathrm{Cu}$

- Trace metals in Armandia brevis correlated with sedimentary reactive trace metals

\section{A R T I C L E I N F O}

\section{Article history:}

Received 25 June 2015

Received in revised form 4 November 2015

Accepted 6 November 2015

Available online 18 November 2015

Editor: F.M. Tack

\section{Keywords:}

Speciation

Trace metal

Sediment contamination

Pyrite

Armandia brevis
G R A P H I C A L A B S T R A C T

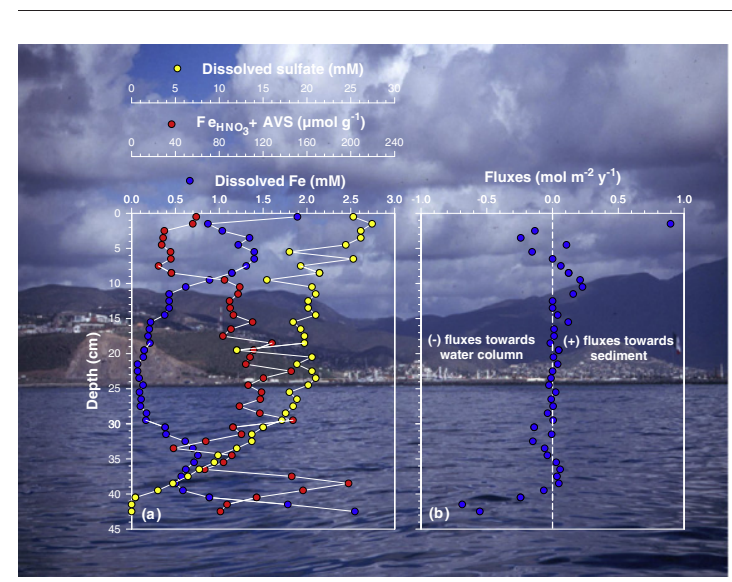

\section{A B S T R A C T}

Trace metals ( $\mathrm{Cd}, \mathrm{Co}, \mathrm{Cu}, \mathrm{Fe}, \mathrm{Mn}, \mathrm{Ni}, \mathrm{Pb}, \mathrm{Zn}$ ) were determined in two operationally defined fractions ( $\mathrm{HCl}$ and pyrite) in sediments from Ensenada and El Sauzal harbors (Mexico). The $\mathrm{HCl}$ fraction had significantly higher metal concentrations relative to the pyrite fraction in both harbors, underlining the weak tendency of most trace metals to associate with pyrite. Exceptionally, $\mathrm{Cu}$ was highly pyritized, with degrees of trace metal pyritization (DTMP) $>80 \%$ in both harbors. Dissolved Fe flux measurements combined with solid phase Fe sulfide data indicated that $98 \mathrm{mt}$ of $\mathrm{Fe}$ are precipitated as iron sulfides every year in Ensenada Harbor. These Fe sulfides (and associated trace metals) will remain preserved in the sediments, unless they are perturbed by dredging or sediment resuspension. Calculations indicate that dredging activities could export to the open ocean $0.20 \pm 0.13$ to $(0.30 \pm 0.56) \times 10^{3} \mathrm{mt}$ of $\mathrm{Cd}$ and $\mathrm{Cu}$, respectively, creating a potential threat to marine benthic organisms. Degrees of pyritization (DOP) values in Ensenada and El Sauzal harbors were relatively low $(<25 \%)$ while degrees of sulfidization (DOS) were high ( $50 \%$ ) because of the contribution of acid volatile sulfide. DOP values correlated with DTMP values $(p \leq 0.001)$, indicating that metals are gradually incorporated into pyrite as this mineral is formed. Significant correlations were also found between DTMP values and $-\log \left(\mathrm{K}_{\mathrm{sp}(\mathrm{Mes})} / \mathrm{K}_{\mathrm{sp}(\mathrm{pyr})}\right)$ for both harbors, indicating that incorporation of trace metals into the pyrite phase is a function of the solubility product of the corresponding metal sulfide. The order in which elements were pyritized in both harbors was $\mathrm{Zn} \approx \mathrm{Mn}<\mathrm{Fe}<\mathrm{Cd} \approx \mathrm{Pb}<\mathrm{Ni} \approx \mathrm{Co}<<\mathrm{Cu}$. Lastly, a strong correlation $\left(r^{2}=0.87, p<0.01\right)$ was found between average reactive trace metal concentrations and metal concentrations measured in Armandia brevis (a deposit-

\footnotetext{
* Corresponding author.

E-mail address: huertam@uabc.edu.mx (M.A. Huerta-Diaz).
} 
feeding Opheliid polychaete), suggesting that these labile sedimentary metals are preferentially accumulated by the polychaete, making it a useful biomonitor of sedimentary metal exposure.

(c) 2015 Elsevier B.V. All rights reserved.

\section{Introduction}

Commercial harbors are often impacted by contaminants from industrial, urban and shipping activities. Among such contaminants, trace metals can be present in high concentrations in sediments where they can be accumulated by burrowing animals and be toxic to them (Luoma and Rainbow, 2008). Furthermore, they can be transferred along food chains thereby affecting fish and their predators, including humans (Hare, 1992). Given this potential for contaminating marine ecosystems, it is important to measure the geochemistry of sedimentary trace metals, so as to estimate their bioavailability (Luoma and Rainbow, 2008). Predictions of bioavailability can then be tested by measuring these contaminants in invertebrates feeding on and burrowing in sediments (Phillips and Rainbow, 1993).

Sediments tend to be sinks for trace metals in coastal marine environments (Díaz-de-Alba et al., 2011; Sarkar et al., 2014). Sediment contamination is of special concern in harbor areas, which are low-energy environments characterized by the presence of high metal inputs from marinas, boat maintenance, fish markets, shipping activities, and industrial, storm and urban discharges (Huerta-Diaz et al., 2008). Additionally, alteration of the original morphology due to the construction of new infrastructure creates areas of low hydrodynamic energy, where sediments and associated contaminants can accumulate (Bocchetti et al., 2008; Montero et al., 2013). Most importantly, harbors are zones that are regularly dredged in order to keep them open for ship navigation, disrupting in the process redox conditions, and remobilizing metals from the sediments, which can then become available to marine organisms (Eggleton and Thomas, 2004). Thus, an accurate assessment and management of contaminated sediments from harbors is required (Bocchetti et al., 2008).

It is generally accepted that the determination of total metal concentrations in sediments is not predictive of their mobility in the environment, their availability to burrowing animals, or their capacity to form other mineral phases. Metal uptake by benthic animals depends on the metal species present in sediments (Flores-Rodríguez et al., 1994; Wang et al., 1999; Rainbow, 2002), the burrowing and feeding behavior of the animals (Michaud et al., 2005; Martin et al., 2008) as well as their gut chemistry (Chen et al., 2000; Michaud et al., 2005). Hence, solid phase speciation influences metal accumulation by sediment-dwelling animals and thus the potential for toxic effects (Gonzalvez et al., 2009). Trace metals in uncontaminated sediments are relatively immobile because they are bound mainly to silicates and primary minerals (e.g., feldspars, micas, quartz), whereas in highly contaminated sediments trace elements are generally more labile and, therefore, likely to be more bioavailable. A number of extraction procedures have been developed to determine the reactivity of sedimentary trace elements (e.g., Sahuquillo et al., 2003). Thus Huerta-Diaz and Morse (1990) developed a chemical sequential extraction scheme to separate trace metals associated with three operationally defined fractions, which will be henceforth named (e.g., Huerta-Diaz et al., 2011, 2014) HCl (metals nominally associated with carbonates, Fe and Mn oxyhydroxides and acid volatile sulfide or AVS), silicate (mainly clays, which react little during early diagenesis) and pyrite (mainly metals associated with this mineral phase). Hence, measurements of trace elements associated with the $\mathrm{HCl}$ and pyrite fractions are useful for estimating the amounts of reactive trace metals that can be released into the environment subsequent to a change in redox conditions.

This study was carried out in the reduced sediments of two harbors (Ensenada and El Sauzal) located on the Pacific coast of Baja California, Mexico. The main objectives of this study were to: (1) measure the concentrations of various trace metals ( $\mathrm{Cd}, \mathrm{Co}, \mathrm{Cu}, \mathrm{Fe}, \mathrm{Mn}, \mathrm{Ni}, \mathrm{Pb}, \mathrm{Zn}$ ) associated with the so-called reactive fraction $(\mathrm{RF}=\mathrm{HCl}+$ pyrite $)$ so as to evaluate the potential for trace element transfer from these sediments to the overlying water column by dredging activities; (2) calculate the degrees of pyritization (DTMP) of the various trace metals so as to determine the extent of association to sedimentary pyrite, which is unstable under oxic conditions; (3) elucidate the formation mechanisms and extent of diagenetic pyrite accumulation in the sediments of the two harbors; (4) quantify the benthic fluxes of dissolved Fe in Ensenada Harbor; and (5) evaluate relationships between the concentrations of trace elements associated with pyrite and reactive fractions and those in Armandia brevis Moore, 1906, a deposit-feeding opheliid polychaete. We chose this annelid as a biomonitor because it is exposed to sedimentary metals both through the ingestion of sediment and during its burrowing activity (Meador and Rice, 2001).

\section{Description of the study areas}

Todos Santos Bay (TSB) is located in the Pacific coast of the Baja California Peninsula, Mexico (Fig. 1a), approximately $100 \mathrm{~km}$ south of the US-Mexico border ( $\left.31^{\circ} 40^{\prime}, 31^{\circ} 56^{\prime} \mathrm{N} ; 116^{\circ} 36^{\prime}, 116^{\circ} 50^{\prime} \mathrm{W}\right)$. This bay is a major fishing area in Mexico, as well as being an important site for tourism, boat repair and maintenance, the culture of mussels (Mytilus galloprovincialis) and abalone (Haliotis sp.) (Curiel-Ramírez and Cáceres-Martínez, 2010), and intense shipping activity originating in Ensenada and El Sauzal Harbors (Fig. 1). The bay also receives seasonal water discharges during the rainy season (winter) from Ensenada Creek (Fig. 1d) and from municipal wastewater discharges all year round (Muñoz-Arriola, 1994; Muñoz-Barbosa et al., 2012). Despite these activities, trace metals are generally present in high concentrations only in the area encompassed by Ensenada harbor, where total metal concentrations can be $1.1(\mathrm{Zn})$ to $14(\mathrm{Cu})$ times the average concentration in TSB (Romero-Vargas-Márquez, 1995). Metal concentrations in the harbors reach levels that can be toxic to the biota (Romero-Vargas-Márquez, 1995; Muñoz-Barbosa et al., 2012). Prior to 2005, large quantities of contaminated sediments were transferred from these harbors to TSB during the dredging of harbor sediments that were routinely dumped in TSB (Carreón-Martínez et al., 2001). After this year, new legislation mandated that dredged sediments should be released outside of the bay. Hence, it is important to estimate the amounts of reactive trace metals that have been transferred into and outside of the bay through the discharge of dredged materials from Ensenada and El Sauzal harbors.

Ensenada Harbor covers $1.95 \mathrm{~km}^{2}$. Water depths range from 1.5 to $11 \mathrm{~m}$, with the deepest zones located close to the loading and terminal docks as well as in the main navigation channel. Metal concentrations in harbor sediments tend to be high due to: (a) the high proportion of finegrained sediments, which gives a high surface area to volume that is favorable for trace metal binding, (b) discharges from a nearby fish market and from marine vessels usually docked at the port and marina areas, (c) seasonal urban runoff from the city of Ensenada through Ensenada Creek during the winter rainy season (Fig. 1d), and (d) inputs from ship repair and maintenance activities that release antifouling agents and residues from sand blasting operations.

El Sauzal Harbor, located $10 \mathrm{~km}$ north of Ensenada in the town of El Sauzal de Rodriguez, covers an area of $0.15 \mathrm{~km}^{2}$ and has water depths ranging from 1 to $9 \mathrm{~m}$, with the maximum depths located in the main navigation channel (Flores-Vidal et al., 2005; Fig. 1c). This harbor receives blood and organic wastes from docked fishing boats and dust generated during the offloading of cement (Huerta-Diaz et al., 2008). 


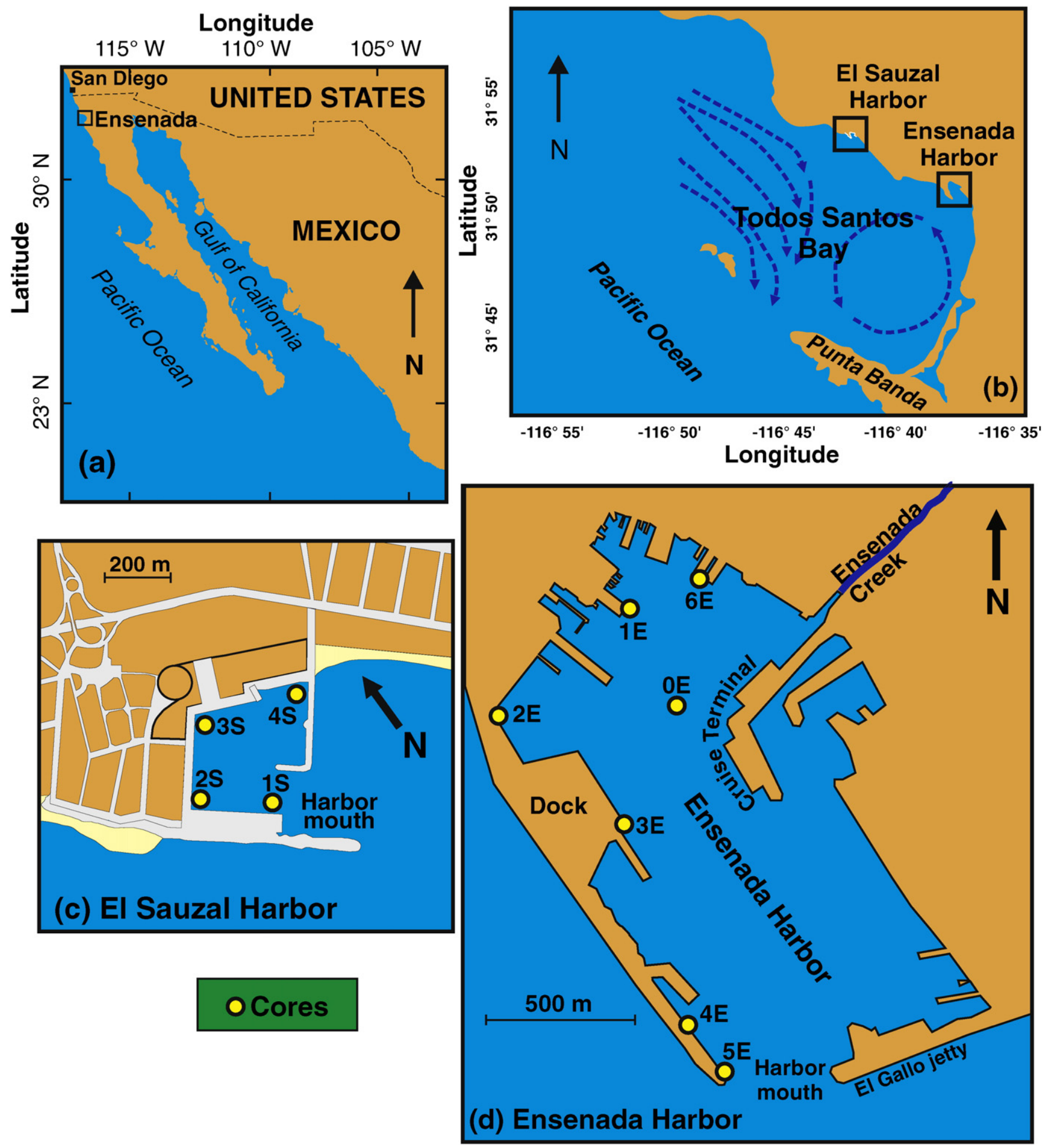

Fig. 1. Location of Ensenada and El Sauzal harbors, showing the position of the collected cores.

\section{Methodology}

All material used in the collection and processing of samples was washed with phosphate-free soap, rinsed three times with distilled water, soaked in a $5 \% \mathrm{HCl}$ bath for $24 \mathrm{~h}$, and then rinsed another three times with deionized water (Milli-Q grade). Materials were dried at room temperature inside a laminar flow hood and all reagents used in this work were reagent grade or better.

\subsection{Sample collection}

All sediment cores were collected by a diver using polycarbonate plastic core liners ( $7.2 \mathrm{~cm}$ internal diameter, $60 \mathrm{~cm}$ in length) that were pushed into the sediment, retrieved and capped underwater. Once on board, the caps of the core liner were sealed with electrical tape and transported to the shore where the sediment was extruded and sectioned into $1-\mathrm{cm}$ intervals with a plastic spatula. Each section 
was then placed in a 50-mL centrifuge polypropylene tube and stored at $-20{ }^{\circ} \mathrm{C}$ until analysis. Seven cores were collected in Ensenada Harbor and four in El Sauzal Harbor (Fig. 1). In Ensenada Harbor, one core (OE) was collected on November 2, 1998, at $\sim 6 \mathrm{~m}$ water depth (Carreón-Martínez et al., 2001), in the dredged channel, near the mouth of Ensenada Creek and the future site of a cruise-ship terminal. The other six cores from Ensenada Harbor (cores 1E to 6E; Fig. 1d) were collected on January 8, 2002, in $~ 9$ m water depth underneath the docks, where sediments are least affected by resuspension and dredging activities. The sediments were generally black in color all along the length of the cores and smelled strongly of $\mathrm{H}_{2} \mathrm{~S}$, with the oxidized portion near the sediment-water interface generally absent, indicating the presence of reducing conditions and large amounts of Fe monosulfides. Sediment cores from El Sauzal Harbor (cores 1S to 4S; Fig. 1c) were collected on September 29, 2004 at water depths ranging from 6 to $9 \mathrm{~m}$. Note that the $10-13 \mathrm{~cm}$ sediment interval in core $2 \mathrm{~S}$ consisted almost entirely of fish scales.

Porewater samples were extracted from each of the 43 sediment sections of core $\mathrm{OE}$ using a mechanical extruder placed inside a glove bag under nitrogen $\left(\mathrm{N}_{2}\right)$ atmosphere to avoid precipitation of the reduced $\mathrm{Fe}$ and $\mathrm{Mn}$ dissolved in the anoxic portion of the porewaters. The glove bag was purged with $\mathrm{N}_{2}$ at least three times before extruding the sediment, and a continuous flux of this gas was kept throughout the extruding process to keep a positive $\mathrm{N}_{2}$ atmosphere within the glove bag. Before sediment extrusion, a water sample was withdrawn from $\sim 0.5 \mathrm{~cm}$ above the sediment-water interface, using Tygon tubing. The sediment core was then sliced at $1-\mathrm{cm}$ intervals and each sample was placed in a $50-\mathrm{mL}$ centrifuge tube, capped and sealed with electrical tape. Next, the glove bag was open and the sealed tubes were centrifuged at $6000 \mathrm{rpm}$ for $30 \mathrm{~min}$. The centrifuged tubes and an equal number of $30-\mathrm{mL}$ plastic bottles containing $20 \mu \mathrm{L}$ of concentrated $\mathrm{HCl}$ were placed inside the glove bag, and the purging process was repeated once more before opening the sealed tubes. The porewater was then poured into plastic syringes fitted with acid-cleaned $0.45 \mu \mathrm{m}$ polyethyleneencapsulated Teflon cellulose membrane filters ( $25 \mathrm{~cm}$ diameter), and the filtrate was placed in the pre-acidified polypropylene bottles. Once placed in these bottles, the glove bag was opened and the porewater samples were stored at $-20^{\circ} \mathrm{C}$ until analyzed.

To obtain the polychaete A. brevis, sediment was collected using an Ekman grab at each sampling site in Ensenada Harbor. The grab's contents were sieved through a $0.5 \mathrm{~mm}$ mesh-aperture net and the residue was put in plastic bags containing seawater for transport to the laboratory where $A$. brevis were removed by hand and their identification confirmed under a dissecting microscope (Luz Verónica Rodriguez-Villanueva, personal communication). Worms were held in seawater for $\sim 12 \mathrm{~h}$ to depurate their gut contents (verified by visual inspection), then 5-7 individuals were placed in a $10 \mathrm{~mL}$ high-density polyethylene bottle for storage prior to freezing at $-20^{\circ} \mathrm{C}$. Five such samples were prepared for each sampling site.

\subsection{Sequential extraction of sediment samples and trace metal analysis}

Sediment samples were subjected to a chemical sequential extraction technique in which three operationally defined fractions were obtained: $\mathrm{HCl}$, silicate and pyrite (Huerta-Diaz and Morse, 1990). A predetermined amount of homogenized wet sediment equivalent to $2.5 \mathrm{~g}$ dry weight, which was previously calculated from the percentage by weight of water and solid for each sample, was used in the digestion procedure. The extraction method consists of the sequential digestion, at room temperature, of the sediment sample with $20 \mathrm{~mL}$ of $1 \mathrm{~N} \mathrm{HCl}$ for $16 \mathrm{~h}$ ( $\mathrm{HCl}$ fraction, which includes trace metals associated with carbonate minerals, Fe and Mn oxyhydroxides and AVS). Afterwards, the silicate fraction was obtained with two successive extractions using $30 \mathrm{~mL}$ of $10 \mathrm{M} \mathrm{HF}$ for 1 and $16 \mathrm{~h}$, respectively. Lastly, the residue from the previous extraction was digested for $1 \mathrm{~h}$ in $10 \mathrm{~mL}$ of concentrated $\mathrm{HNO}_{3}$ (pyrite fraction, which includes trace metals associated with this mineral phase). The silicate fraction was discarded since it contains metals that are considered to be non-reactive during the process of early diagenesis (Huerta-Diaz and Morse, 1992). The sum of the $\mathrm{HCl}$ and pyrite fractions will be henceforth denominated as the reactive or labile fraction (e.g., Huerta-Diaz et al., 2011, 2014), which includes trace metals that can be dissolved, transformed into other mineral phases or incorporated into the marine biota.

The extraction method of Huerta-Diaz and Morse (1990) has been shown to successfully extract metals associated with pyrite in sediments with organic carbon contents $<3 \%$. In sediments with organic carbon contents $>3 \%$, the pyrite fraction may include trace metals associated with this mineral phase as well as with organic matter. However, this limitation does not apply to $\mathrm{Fe}$, since this metal is not associated to a significant extent with sedimentary organic matter. The organic carbon contents of all collected cores were $<3 \%$, except core $2 \mathrm{~S}$ from El Sauzal Harbor that contained up to $6.7 \%$ organic matter (Huerta-Diaz et al., 2008). Thus, trace metal results associated with pyrite for core $2 S$ should be interpreted with caution because some of the metals could have been associated with organic matter.

Trace metal concentrations ( $\mathrm{Cd}, \mathrm{Co}, \mathrm{Cu}, \mathrm{Fe}, \mathrm{Mn}, \mathrm{Ni}, \mathrm{Pb}, \mathrm{Zn}$ ) were measured with a Thermo Jarrel Ash model Smith Hieftje 12 or SpectraAA 220 Fast Sequential flame atomic absorption spectrophotometer. Detection limits (for the $\mathrm{HCl}$ and pyrite fractions, respectively), calculated as three times the standard deviation of the procedural blanks (in nmol g-1), were: Cd $(0.8,0.7)$, Co $(20,18), \mathrm{Cu}(2.6,3.2)$, Fe $(7.4,13.6), \mathrm{Mn}(7.2,9.3)$, $\mathrm{Ni}(14,13), \mathrm{Pb}(2.8,4.1)$ and $\mathrm{Zn}(3.4,2.1)$. Blanks were routinely analyzed and included in each batch of samples, and they were found to be always below their respective detection limits. Although there is no Certified Reference Material (CRM) available to verify the accuracy of the $\mathrm{HCl}$ and pyrite extractions, Huerta-Diaz and Morse (1990) performed an extensive validation of the method that demonstrated quantitative extraction of metals in these two fractions.

AVS analyses were carried out by placing from 0.1 to $0.5 \mathrm{~g}$ of wet sediment in a digestion vessel that was then immediately capped with a rubber stopper with three ports: one where $\mathrm{N}_{2}$ carrier gas entered, the second where the $\mathrm{N}_{2}$ carrying the hydrogen sulfide $\left(\mathrm{H}_{2} \mathrm{~S}\right)$ gas exited, and a third port where the digestion solution was introduced into the flask. The system and the digestion solution were then purged of oxygen using purified $\mathrm{N}_{2}$ gas. Next, $20 \mathrm{~mL}$ of a digestion solution made of $\mathrm{N}_{2}$ purged $1 \mathrm{~N} \mathrm{HCl}$ were introduced into the digestion vessel through the appropriate port and bubbled with $\mathrm{N}_{2}$. The digestion vessel was then shaken for $2 \mathrm{~h}$ with constant $\mathrm{N}_{2}$ bubbling through one of the ports. The $\mathrm{H}_{2} \mathrm{~S}$ gas that evolved from the decomposition of the AVS was trapped as $\mathrm{ZnS}$ in a $100 \mathrm{~mL}$ volumetric flask filled with $8 \mathrm{~mL}$ of $0.27 \mathrm{M}$ $\mathrm{Zn}$ acetate solution and $56 \mathrm{~mL}$ of distilled water. After $2 \mathrm{~h}$, the digestion was stopped and $8 \mathrm{~mL}$ of Cline's reagent (Cline, 1969) were added to the volumetric trapping flasks, followed by addition of enough $6 \mathrm{~N} \mathrm{HCl}$ to bring the volume of the solution to $100 \mathrm{~mL}$. The concentrations of the resulting methylene blue solutions were determined colorimetrically at $670 \mathrm{~nm}$ with a 1-cm cell using a Varian Cary 50 UV-Vis spectrophotometer. The standards for the calibration curve were prepared from a $0.08 \mathrm{M}$ sodium sulfide stock solution which was then diluted by $1 / 10$ after adding $200 \mu \mathrm{L}$ of $\mathrm{NaOH}$ to the new solution. This diluted solution was then used to prepare a series of calibration standards. Water used for all stock and standard solutions was previously purged with $\mathrm{N}_{2}$. The AVS concentration, on a dry weight basis, was calculated from the percentage of water in the sample. The detection limit of this method was $0.04 \mu \mathrm{M}$, equivalent to approximately $4 \mathrm{nmol}$ AVS per gram of dry sediment, with a precision of $\pm 3 \%$ at the $95 \%$ confidence level. The Fe concentrations associated with the AVS $\left(\mathrm{Fe}_{\mathrm{AVS}}\right)$ were calculated by assuming that the AVS is composed entirely of FeS.

\subsection{Dissolved $\mathrm{Fe}^{2+}$ and sulfate analysis in pore water}

Dissolved $\mathrm{Fe}^{2+}$ concentrations were determined using the ferrozine colorimetric technique described by Stookey (1970) and Gibbs (1979) 
which, briefly, consists of adding the ferrozine complexing agent to water and pore water samples in the presence of the reducing agent hydroxylamine hydrochloride. The Fe-complex formed was analyzed spectrophotometrically at $562 \mathrm{~nm}$ using a Varian Cary 50 UV-Vis spectrophotometer.

Porewater sulfate concentrations were measured using the gravimetric method of Howarth (1978), which consists of the addition of $\mathrm{BaCl}_{2}$ to the sample and the subsequent precipitation of the dissolved sulfate as $\mathrm{BaSO}_{4}$. The $\mathrm{BaSO}_{4}$ is then removed by filtration and weighed in order to calculate the sulfate concentration in porewater. This method has a detection limit of approximately $0.3 \mathrm{mM}$. Sulfate recoveries using Copenhagen seawater with a known salinity, were $110 \pm 5 \%(n=3)$.

\subsection{Metal analyses in A. brevis}

Frozen samples of $A$. brevis were freeze-dried (FTS Systems), weighed on a micro-balance (Mettler ME30) and digested in concentrated, Aristar grade, $\mathrm{HNO}_{3}\left(100 \mu \mathrm{L} \mathrm{mg}{ }^{-1}\right.$ dry weight (d.w.) at room

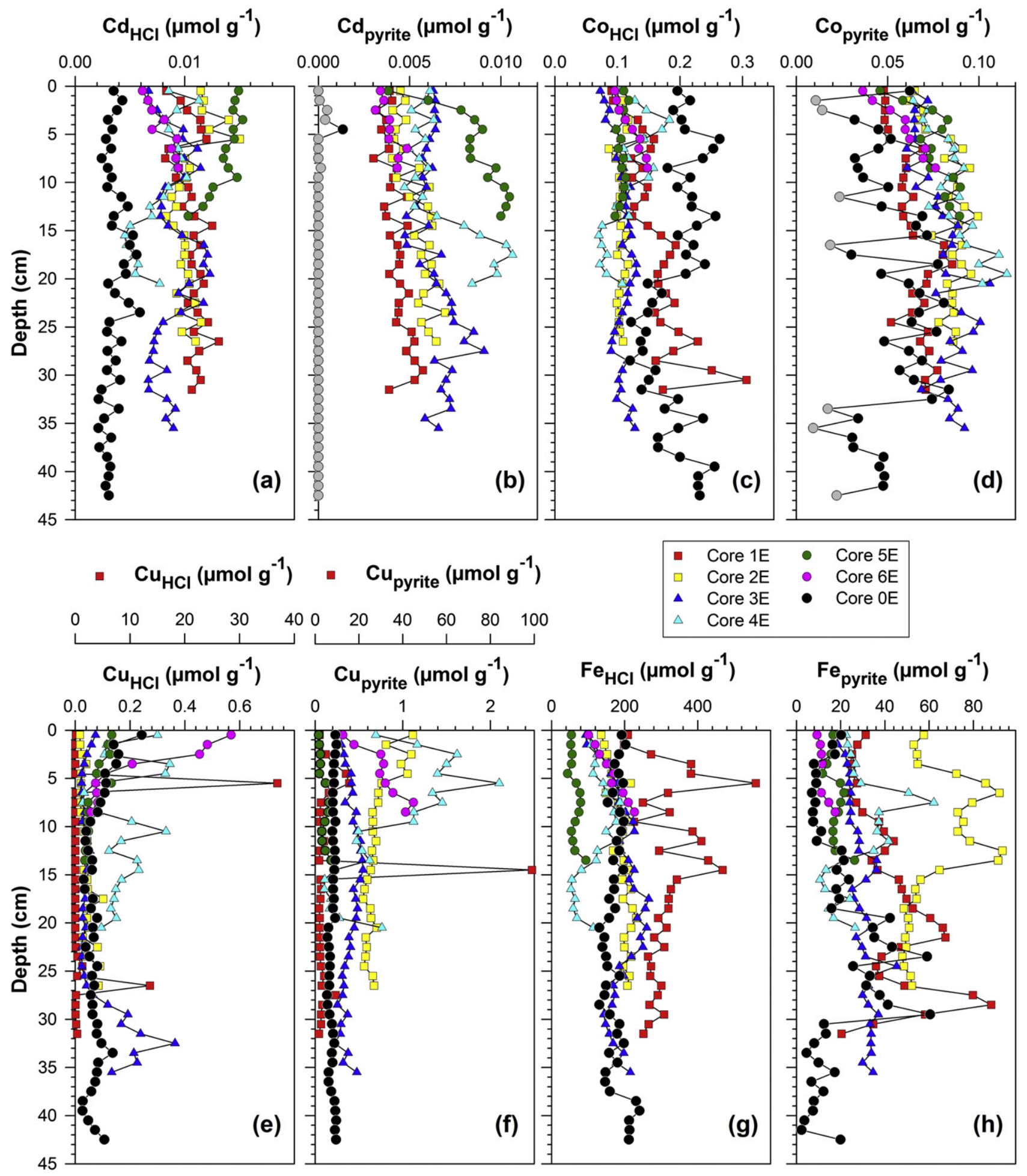

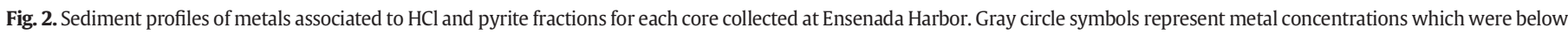
their corresponding detection limit. 


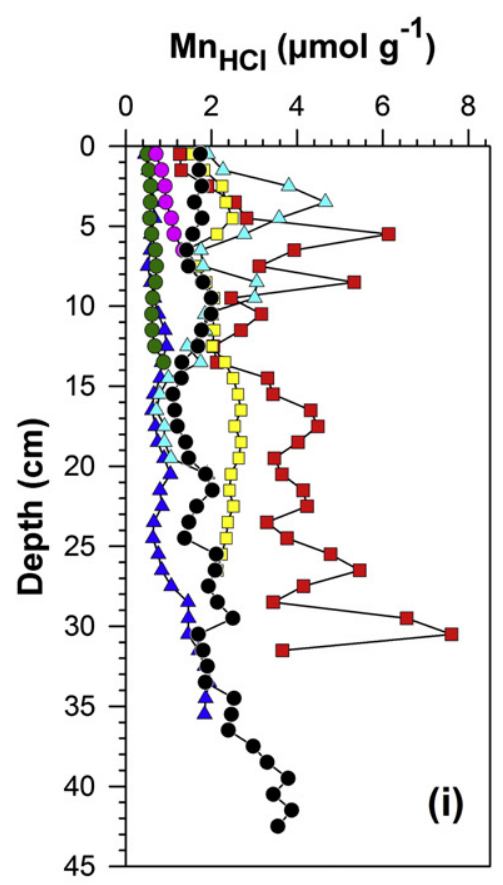

$M n_{\text {pyrite }}\left(\mu \mathrm{mol} \mathrm{g}{ }^{-1}\right)$

$\mathrm{Ni}_{\mathrm{HCl}}\left(\mu \mathrm{mol} \mathrm{g}{ }^{-1}\right)$

$\mathrm{Ni}_{\text {pyrite }}\left(\mu \mathrm{mol} \mathrm{g}{ }^{-1}\right)$
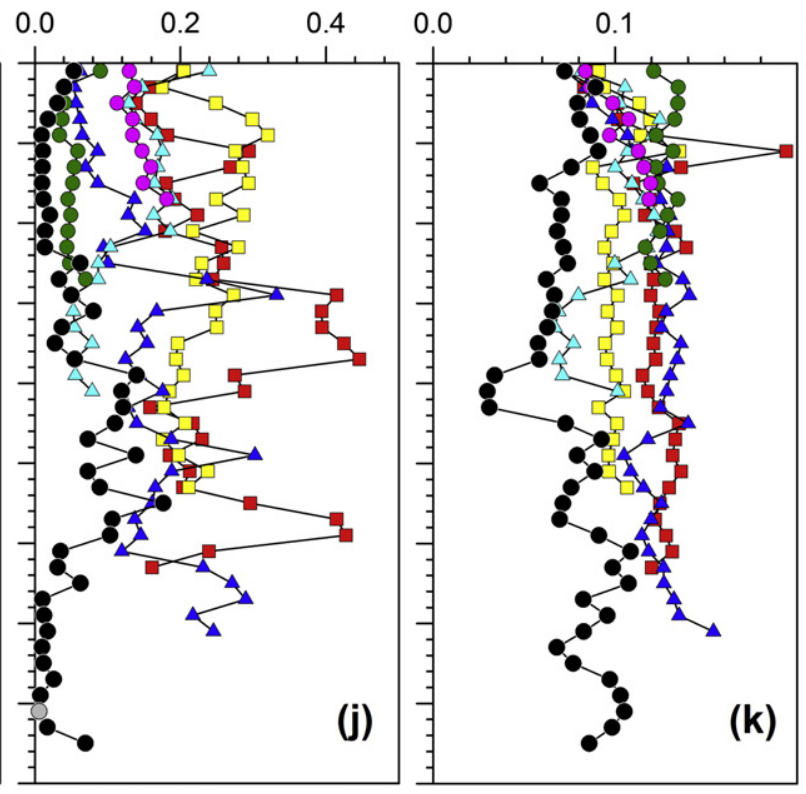

$0.00 \quad 0.05$

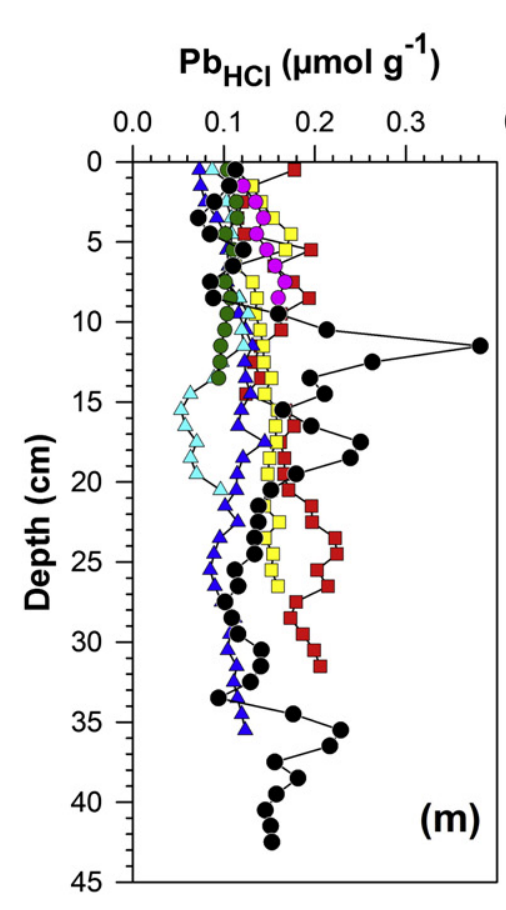

$\mathrm{Pb}_{\text {pyrite }}\left(\mu \mathrm{mol} \mathrm{g}{ }^{-1}\right)$

$\mathrm{Zn}_{\mathrm{HCl}}\left(\mu \mathrm{mol} \mathrm{g}{ }^{-1}\right)$

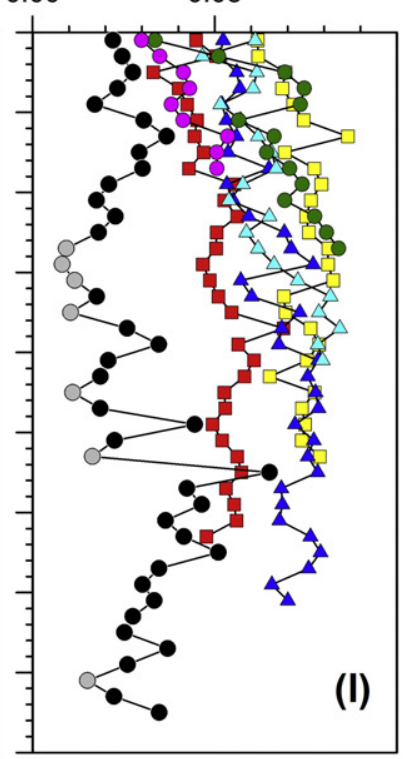

(I)
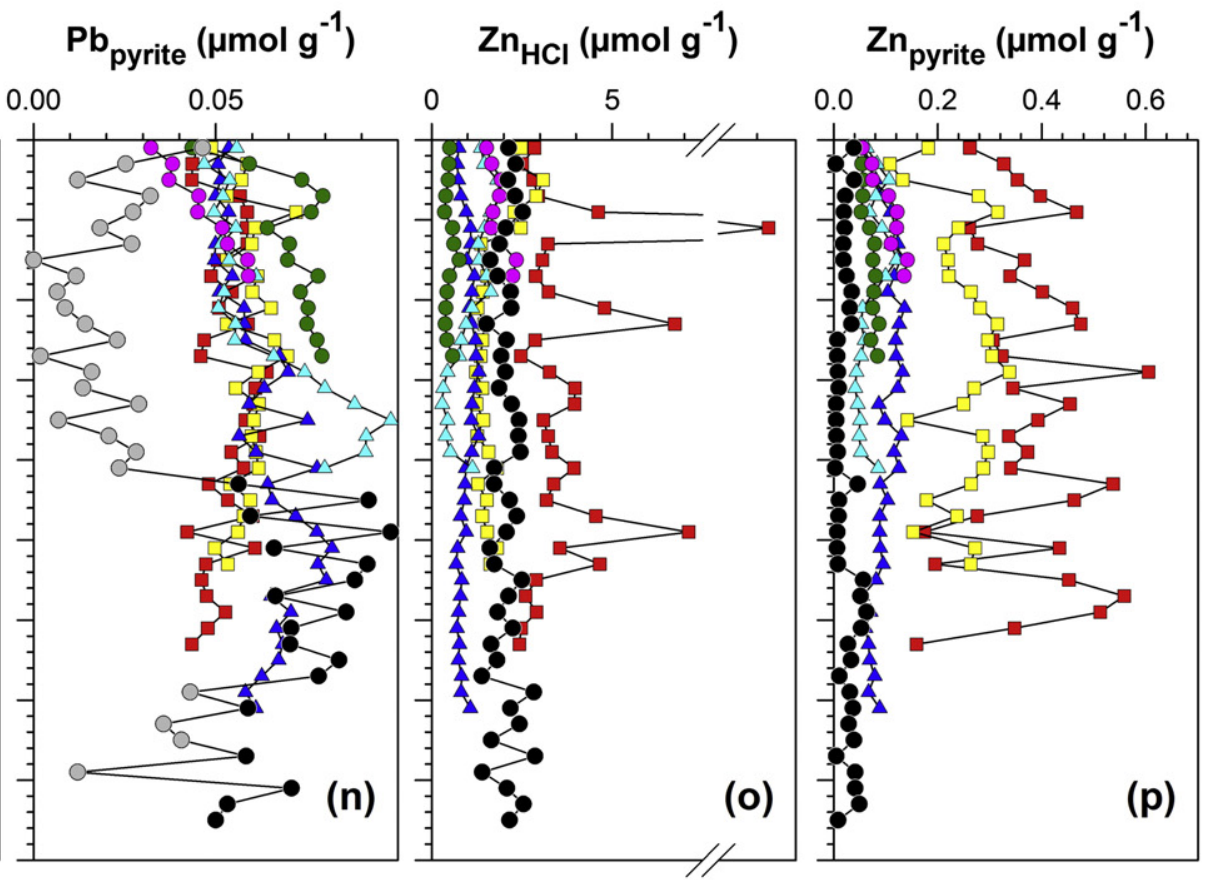

Fig. 2 (continued).

temperature in 4-mL HDPE vials for $7 \mathrm{~d}$. Hydrogen peroxide ( $40 \mu \mathrm{L} \mathrm{mg}^{-1}$ d.w.) was added $24 \mathrm{~h}$ prior to final dilution with ultrapure water $\left(760 \mu \mathrm{L} \mathrm{mg}^{-1}\right.$ d.w.). We submitted samples of similar weight of a certified reference material (lobster hepatopancreas, TORT-1, National Research Council of Canada) to the same digestion procedure during each run. Trace metals were measured by flameless AAS (Varian Spectra AA-30). Trace metal concentrations measured for TORT-1 were within the certified ranges and the recovery of trace metals in spiked samples was within $10 \%$ of the amount added.

\subsection{Data analysis}

The degree of pyritization (DOP) of sediments (Berner, 1970) was used to evaluate the amount of Fe present as pyrite relative to the "reactive Fe" $\left(\mathrm{Fe}_{\mathrm{reac}}=\mathrm{Fe}_{\mathrm{HCl}}+\mathrm{Fe}_{\mathrm{pyr}}\right)$. The DOP was calculated using the following equation:

$\mathrm{DOP}(\%)=\frac{\mathrm{Fe}_{\mathrm{pyr}}}{\mathrm{Fe}_{\mathrm{HCl}}+\mathrm{Fe}_{\mathrm{pyr}}} \times 100=\frac{\mathrm{Fe}_{\mathrm{pyr}}}{\mathrm{Fe}_{\text {Reac }}} \times 100$

where the terms $\mathrm{Fe}_{\mathrm{HCl}}, \mathrm{Fe}_{\mathrm{pyr}}$ and $\mathrm{Fe}_{\text {reac }}$ represent the concentrations of $\mathrm{Fe}$ in the $\mathrm{HCl}$, pyrite and reactive fractions, respectively. Similar to the DOP, the degree of sulfidization (DOS) represents the percentage of reactive Fe that is bound to sulfides and was calculated using the equation (Boesen and Postma, 1988):

$\operatorname{DOS}(\%)=\frac{\mathrm{Fe}_{\mathrm{pyr}}+\mathrm{Fe}_{\mathrm{AVS}}}{\mathrm{Fe}_{\mathrm{HCl}}+\mathrm{Fe}_{\mathrm{pyr}}} \times 100=\frac{\mathrm{Fe}_{\mathrm{pyr}}+\mathrm{Fe}_{\mathrm{AVS}}}{\mathrm{Fe}_{\text {Reac }}} \times 100$. 
The concept of degree of trace metal pyritization (DTMP) was introduced by Huerta-Diaz and Morse (1990) as a measure of the amount of metal $(\mathrm{Me})$ associated with pyrite $\left(\mathrm{Me}_{\mathrm{pyr}}\right)$ relative to "reactive $M e "\left(\mathrm{Me}_{\text {reac }}=\mathrm{Me}_{\mathrm{HCl}}+\mathrm{Me}_{\mathrm{pyr}}\right)$. The DTMP can be calculated using the following equation:

$\operatorname{DTMP}(\%)=\frac{\mathrm{Me}_{\text {pyr }}}{\mathrm{Me}_{\mathrm{HCl}}+\mathrm{Me}_{\mathrm{pyr}}} \times 100=\frac{\mathrm{Me}_{\mathrm{pyr}}}{\mathrm{Me}_{\text {Reac }}} \times 100$

where the term $\mathrm{Me}_{\mathrm{HCl}}$ represents the concentration of a given metal in the $\mathrm{HCl}$ fraction. Due to the higher organic carbon contents in the sediments from core $2 \mathrm{~S}$, our DTMP values may be higher than the actual ones, since DTMP calculations involve the use of only those concentrations associated to pyrite.

Statistical analyses were performed using the STATISTICA 7 Software package (STATSOFT 2004, Inc., USA). Normality of distribution and homogeneity of the data were tested by means of the KolmogorovSmirnov test for normality and by the Lavene and Brown and the Forsythe tests for homogeneity. These tests showed that our data were neither normally distributed nor homogeneous, even after converting them using five different transformations $\left(\log (1+\mathrm{x}), 1 /(1+\mathrm{x}), \mathrm{x}^{2}, \mathrm{x}^{1 / 2}\right.$ and $\operatorname{Ln}(\mathrm{x}))$. Consequently, non-parametric tests were performed. Significant differences among harbors, cores and fractions were tested by Kruskal-Wallis Rank test $(p<0.05)$ and multiple comparison tests

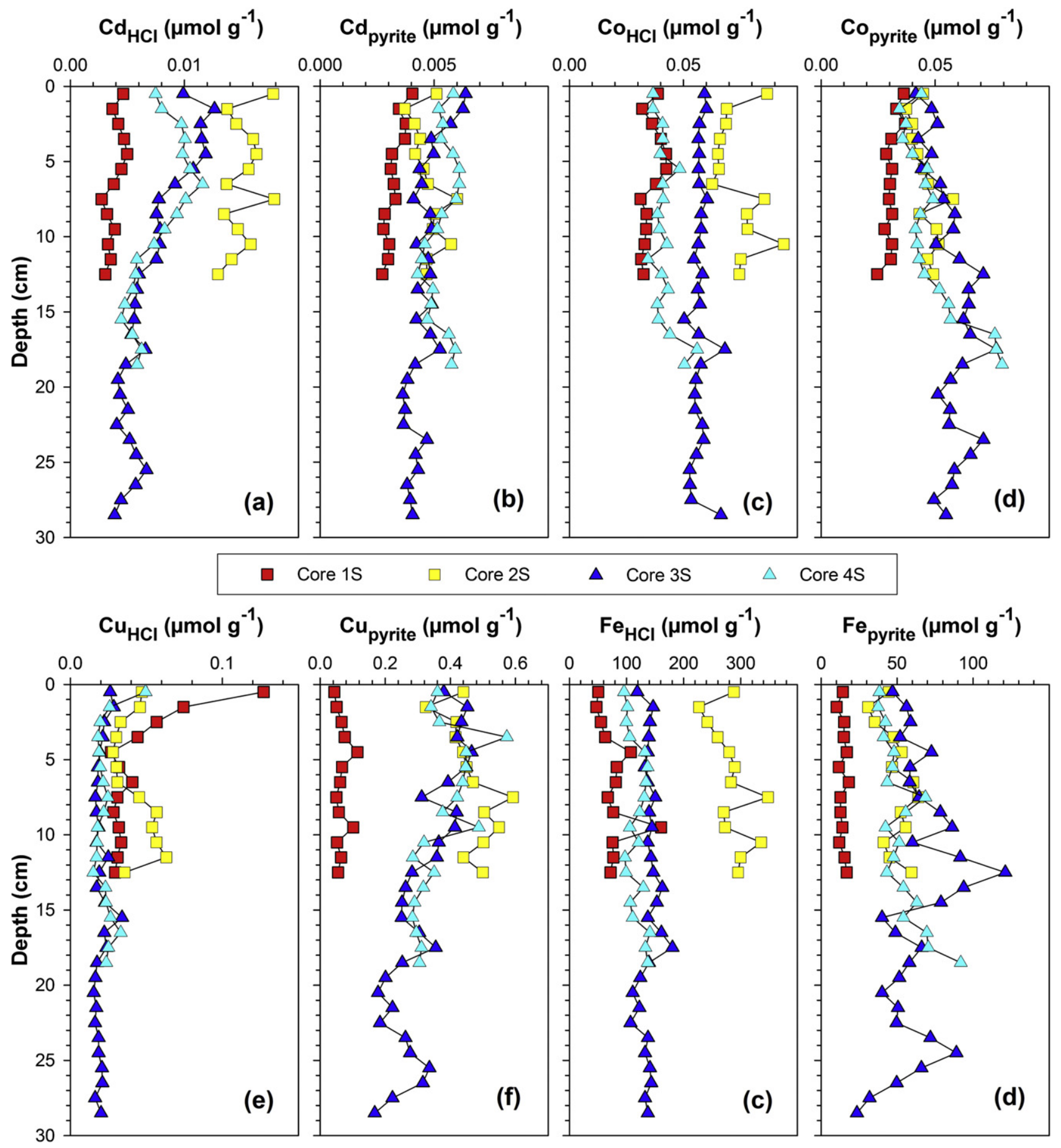

Fig. 3. Sediment profiles of metals associated to $\mathrm{HCl}$ and pyrite fractions for each core collected at El Sauzal Harbor. 

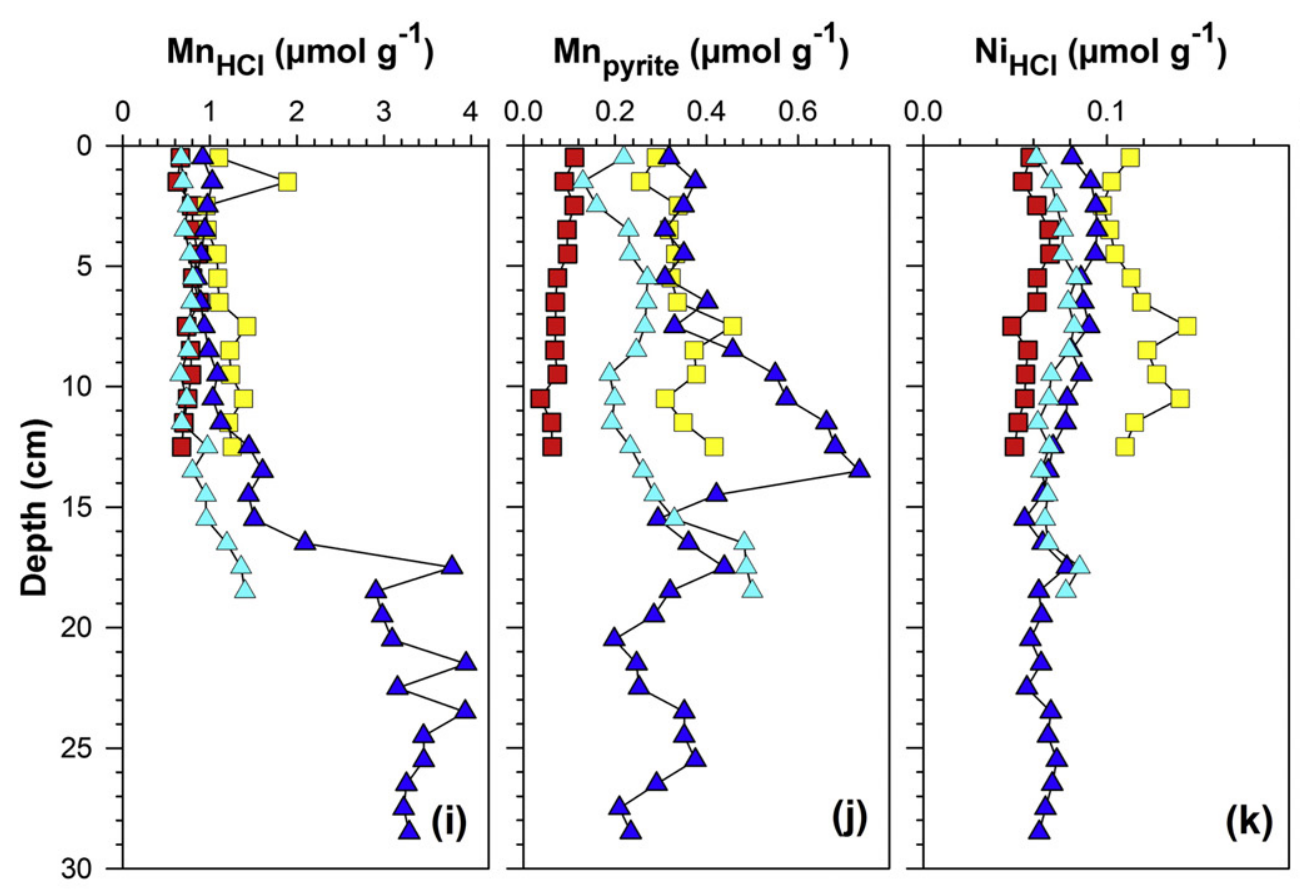

$\mathrm{Ni}_{\text {pyrite }}\left(\mu \mathrm{mol} \mathrm{g} \mathrm{g}^{-1}\right)$
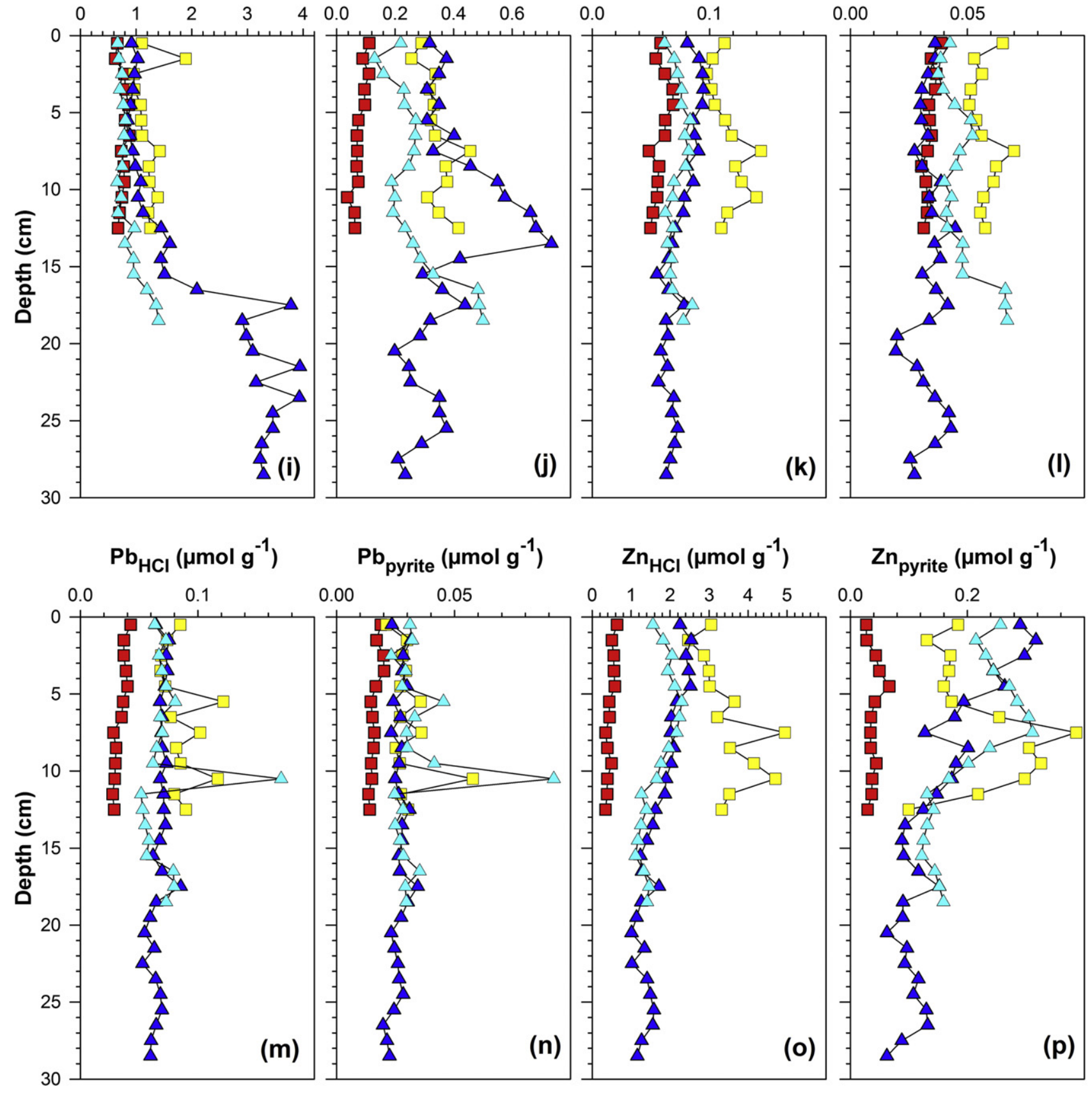

Fig. 3 (continued).

$(p<0.05)$, whereas correlations among the data were calculated by the Spearman's Rank correlation $(p<0.05$ and $p \leq 0.001$ ) to determine the behavioral similarities among the different trace metals.

\section{Results and discussion}

\section{1. $\mathrm{HCl}$, pyrite, and reactive fractions in Ensenada and El Sauzal Harbors}

Profiles for the $\mathrm{HCl}$ and pyrite fractions in Ensenada Harbor (Fig. 2) were somewhat variable, with some metals (e.g., $\mathrm{Cd}_{\mathrm{pyr}}, \mathrm{Co}_{\mathrm{pyr}}, \mathrm{Fe}_{\mathrm{pyr}}$, $\mathrm{Mn}_{\mathrm{HCl}}, \mathrm{Mn}_{\mathrm{pyr}}, \mathrm{Ni}_{\mathrm{pyr}}, \mathrm{Pb}_{\mathrm{HCl}}$, ) showing slight concentration increases with depth, while others remained more or less constant, with their values changing around an average concentration (e.g., $\mathrm{Cd}_{\mathrm{HCl}}, \mathrm{Co}_{\mathrm{HCl}}$, $\left.\mathrm{Fe}_{\mathrm{HCl}}, \mathrm{Ni}_{\mathrm{HCl}}, \mathrm{Zn}_{\mathrm{HCl}}, \mathrm{Zn}_{\mathrm{pyr}}\right)$. Anomalous values were observed at $5.5 \mathrm{~cm}$ depth in core $1 \mathrm{E}$ for $\mathrm{Cu}_{\mathrm{HCl}}$ and, to a certain extent, also for $\mathrm{Fe}_{\mathrm{HCl}}, \mathrm{Ni}_{\mathrm{HCl}}$ and $\mathrm{Zn}_{\mathrm{HCl}}\left(36.9,559,0.194\right.$ and $21.5 \mu \mathrm{mol} \mathrm{g}^{-1}$, respectively), probably produced by mine wastes from a copper mine complex located in Santa Rosalia (Baja California Sur, Mexico) that were used for sandblasting ships. It is interesting to note that our $5.5 \mathrm{~cm}$ peaks for $\mathrm{Cu}$ and $\mathrm{Zn}$ were also reported for total concentrations at the same sediment depth by Huerta-Diaz et al. (2008). Sediments were anoxic-sulfidic up to the sediment-water interface, as indicated by the strong $\mathrm{H}_{2} \mathrm{~S}$ smell of most of the collected sediments and by the absence of significant trace metal enrichments in the $\mathrm{HCl}$ fraction (where Fe oxyhydroxides are normally extracted) close to the sediment-water interface. Hence, it is unlikely that near-surface values were influenced by bioturbation processes since $\mathrm{H}_{2} \mathrm{~S}$ is toxic to invertebrates. Sediment patterns in El Sauzal Harbor for the $\mathrm{HCl}$ and pyrite fractions (Fig. 3) were more homogeneous, with 
TIm $\square$ Location (HCl fraction)

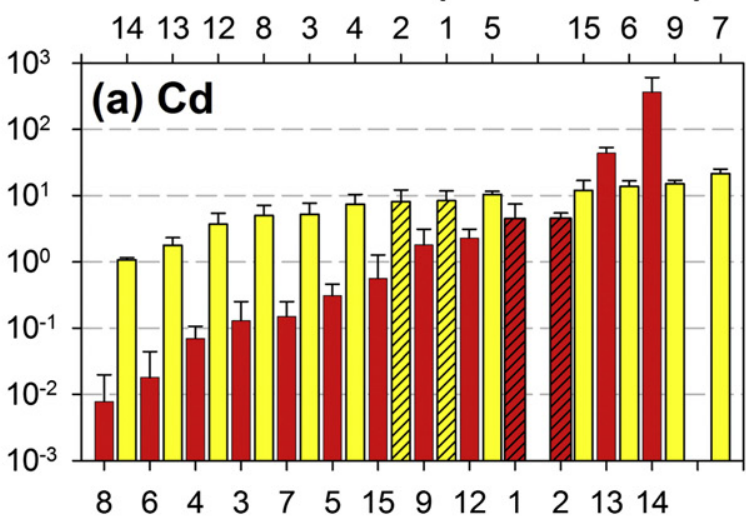

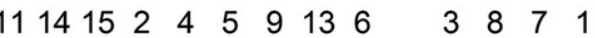
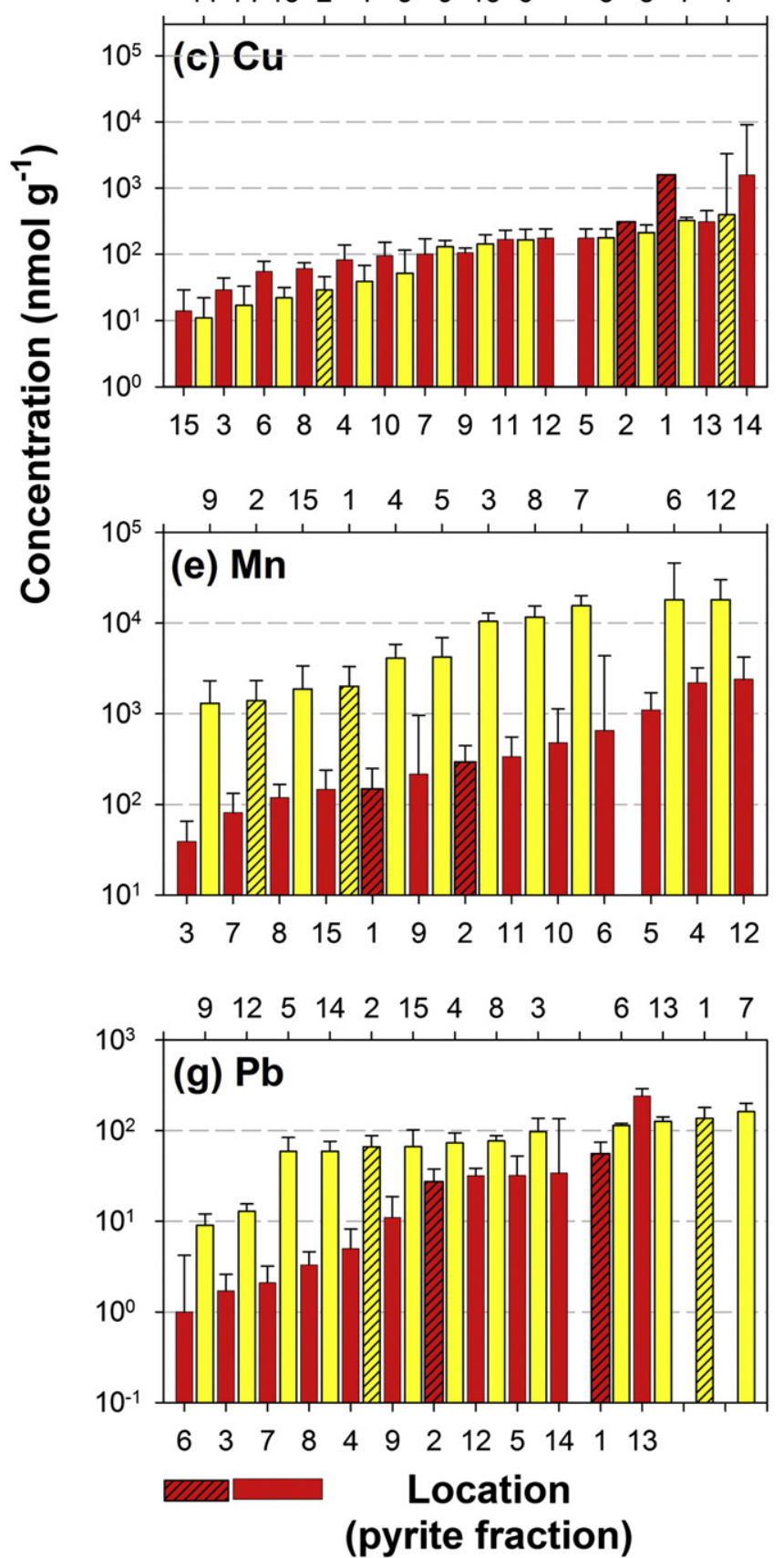

Location ( $\mathrm{HCl}$ fraction)
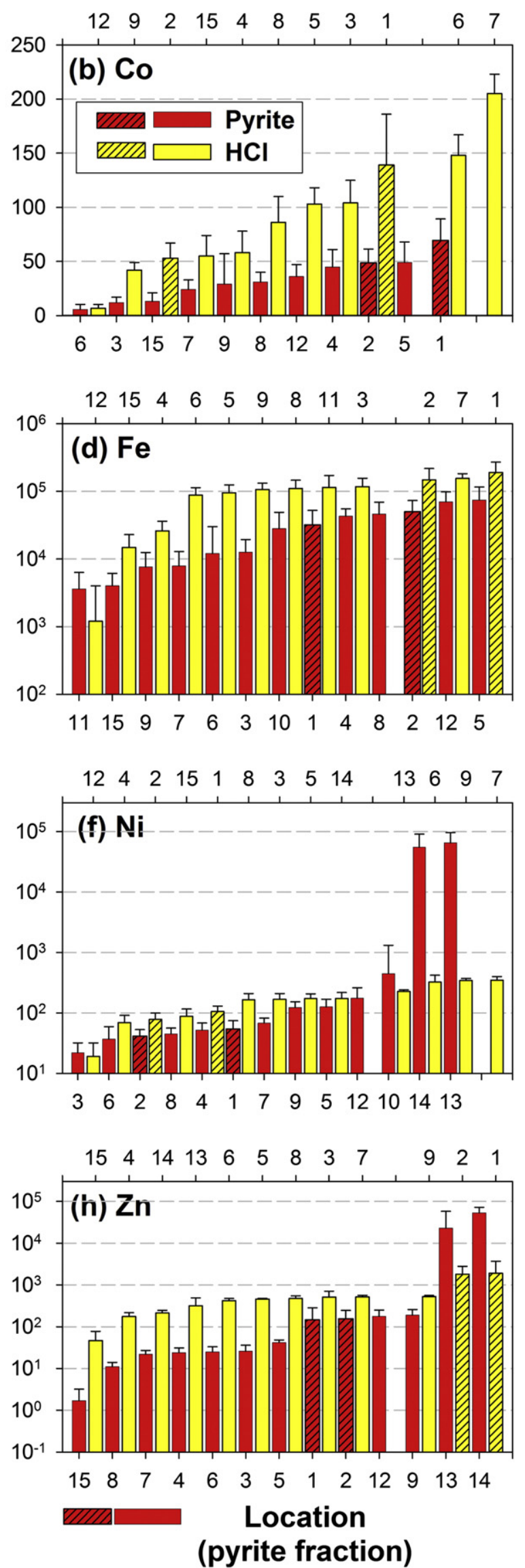
concentrations remaining more or less constant or decreasing slightly with depth, except for Mn which increased below $15.5 \mathrm{~cm}$ for cores $3 \mathrm{~S}$ and 4 , probably because of its precipitation as $\mathrm{MnCO}_{3}$. Peaks of maximum concentration for $\mathrm{Pb}$ in the $\mathrm{HCl}$ and pyrite fractions were observed at a depth of $10.5 \mathrm{~cm}$ ( 0.171 and $0.092 \mu \mathrm{mol} \mathrm{g}^{-1}$, respectively) for core $4 \mathrm{~S}$. Similarly to the Ensenada Harbor sediments, no significant trace metal enrichments were observed close to the sediment-water interface suggesting that the cores were also anoxic up to the sediment-water interface.

Overall average metal concentrations in the $\mathrm{HCl}$ and pyrite fractions in both harbors (Tables A1 and A2, respectively), showed a wide range of values, with the highest ones corresponding to the $\mathrm{HCl}$ fraction (range of $0.008 \pm 0.004$ to $190 \pm 81 \mu \mathrm{mol} \mathrm{g}^{-1}$ for Cd and Fe, respectively) for all metals except $\mathrm{Cu}$, which tended to accumulate in the pyrite fraction (range of $0.0046 \pm 0.0009$ to $50 \pm 23 \mu \mathrm{mol} \mathrm{g}^{-1}$ for Cd and Fe, respectively). In fact, statistical analysis revealed significant differences $(p<0.05)$ between both fractions for all the analyzed metals in the two harbors, with the exception of Co in El Sauzal Harbor. Overall, metal concentrations in the Ensenada Harbor (Tables A1 and A2) indicated similar ranks for the $\mathrm{HCl}(\mathrm{Fe}>\mathrm{Mn} \approx \mathrm{Zn}>\mathrm{Cu}>\mathrm{Co}>\mathrm{Pb}>\mathrm{Ni}>\mathrm{Cd})$ and pyrite $(\mathrm{Fe}>\mathrm{Cu}>\mathrm{Zn} \approx \mathrm{Mn}>\mathrm{Co}>\mathrm{Pb} \approx \mathrm{Ni}>\mathrm{Cd})$ fractions. A similar trend was observed for El Sauzal Harbor (Tables A1 and A2), where the ranks were also similar for the $\mathrm{HCl}(\mathrm{Fe}>\mathrm{Zn}>\mathrm{Mn}>\mathrm{Ni}>\mathrm{Pb}>\mathrm{Co}>\mathrm{Cu}>\mathrm{Cd})$ and pyrite $(\mathrm{Fe}>\mathrm{Cu} \approx \mathrm{Mn}>\mathrm{Zn}>\mathrm{Co}>\mathrm{Ni}>\mathrm{Pb}>\mathrm{Cd})$ fractions. Average (all cores combined) reactive trace metal concentrations increased in the order $\mathrm{Cd}<\mathrm{Ni}<\mathrm{Pb}<\mathrm{Co}<\mathrm{Cu} \approx \mathrm{Zn} \approx \mathrm{Mn} \ll \mathrm{Fe}$ in Ensenada Harbor $(n=182)$, whereas in El Sauzal Harbor $(n=74)$ the order was $\mathrm{Cd}<\mathrm{Pb}<\mathrm{Co}<\mathrm{Ni}<\mathrm{Cu}<\mathrm{Mn} \approx \mathrm{Zn} \ll \mathrm{Fe}$.

Comparison of our average trace metal concentrations in the $\mathrm{HCl}$ fraction with values reported from different selected geographical locations (Fig. 4) showed that $\mathrm{Cd}$ in both harbors and $\mathrm{Pb}$ in El Sauzal Harbor had concentrations that were located approximately in the middle of the range of the selected values. Iron and $\mathrm{Zn}$ for both harbors and $\mathrm{Co}, \mathrm{Cu}$ and $\mathrm{Pb}$ for Ensenada Harbor, however, presented concentrations that were among the highest shown for the selected locations. Only Mn and Ni for both harbors and $\mathrm{Co}$ and $\mathrm{Cu}$ for El Sauzal Harbor showed low values relative to the selected locations. The low values of $\mathrm{Mn}$ in the $\mathrm{HCl}$ fraction can be ascribed to the impoverishment of Mn oxides (which are included in this fraction) produced by their reductive dissolution, the subsequent release of the reduced $\mathrm{Mn}^{2+}$ to the water column by diffusive processes, and to their slow kinetics of precipitation (Yeats and Bewers, 1985; Davies and Morgan, 1989). The low values of $\mathrm{Ni}$ in the $\mathrm{HCl}$ fraction tend to support this hypothesis, since a close association of this element with Mn oxides has been previously reported (e.g., Laslett and Balls, 1995; Sañudo-Wilhelmy and Gill, 1999; Hatje et al., 2003).

To appreciate the concentration differences between both harbors and between the different cores, results for the $\mathrm{HCl}$ and pyrite fractions are shown in the form of Box-Whisker plots (Fig. 5). According to this figure, the concentrations of most metals in the $\mathrm{HCl}$ and pyrite fractions were higher in sediments from Ensenada Harbor compared to those from El Sauzal Harbor, except for Cd and Zn, whose concentrations in the $\mathrm{HCl}$ fraction were similar in both harbors. According to a KruskalWallis Rank test, significant differences $(p<0.05)$ were found between the two harbors for all metals in both fractions, except for $\mathrm{Cd}$ and $\mathrm{Zn}$ in the $\mathrm{HCl}$ fraction. These results indicate that the Ensenada Harbor is, on average, more enriched in reactive trace metals, probably because this harbor is approximately 30 years older than El Sauzal Harbor and, therefore has had more time to accumulate trace metals in the reactive fraction. No spatial trends were found among the various sampling sites in Ensenada or El Sauzal Harbors, except for Fe, Mn and Zn, which showed a decrease in concentration from the inner part of the Ensenada Harbor towards its mouth. In fact, statistical analysis showed significant differences for these metals between core $5 \mathrm{E}$ (located at the mouth and, therefore, under conditions of higher water oxygenation and recirculation rates) and cores $1 \mathrm{E}, 2 \mathrm{E}$ and $3 \mathrm{E}$ (located in the inner part of the harbor; Fig. 1). Moreover, there were also significant differences between core $0 \mathrm{E}$ and the rest of the cores for all metals except Co. These differences can be due to the location of core $0 \mathrm{E}$, which was collected inside the dredged channel and close to the mouth of Ensenada Creek. The continuous ship traffic and dredging operations probably produced sediment resuspension, which is likely to alter the distribution of some key sediment components, such as nutrients and carbon (Nayar et al., 2007). Additionally, the occasional particulate and dissolved contributions from the seasonal stream could also influence the distribution and levels of these metals in core $\mathrm{OE}$.

Our results indicate that there is a very strong dependency between metals associated with the pyrite fraction and those associated with the $\mathrm{HCl}$ fraction, as expressed by the very significant relationship ( $p \leq 0.001$, $r^{2}=0.80, n=16$ ) found between the average values of metals associated with the $\mathrm{HCl}$ and pyrite fractions in all cores from both harbors:

$\log \left(\mathrm{Me}_{\mathrm{pyr}}\right)=(0.78 \pm 10) \log \left(\mathrm{Me}_{\mathrm{HCl}}\right)-(0.45 \pm 0.14)$

It is important to note that most of the data points were located within the 95\% confidence level of the linear regression curve (dashed lines in Fig. 6). These results indicate that the higher the concentration of a given metal in the $\mathrm{HCl}$ fraction, the higher its concentration will be in the pyrite fraction, a behavior that highlights the dependency of the abundance of trace metals in pyrite on those in the $\mathrm{HCl}$ fraction. Similar relationships have been previously reported for sediments of the Pacific Coast of Baja California, Gulf of Mexico (Nava-López and HuertaDiaz, 2001), and the mining port of Santa Rosalia in Baja California Sur (Huerta-Diaz et al., 2014).

Individual relationships were found between metals in both fractions, percentage of grain size $<62.5 \mu \mathrm{m}$ (\%GS; data taken from Huerta-Diaz et al., 2008) and organic carbon ( $C_{\text {org }}$; data taken from Huerta-Diaz et al., 2008) for both fractions and for both harbors. A Spearman correlation matrix (Table S3) showed that a high percentage of the correlations (76\% and $83 \%$ for Ensenada and El Sauzal Harbors, respectively) were significant ( $p \leq 0.05$ or $p \leq 0.001$ ). These results suggest that similar processes are involved in the incorporation of trace metals into these two fractions, but especially into pyrite since a higher percentage of significant correlations were ascribed to this fraction ( $91 \%$ for both harbors) rather than to the $\mathrm{HCl}$ fraction (61\% and 75\% for Ensenada and El Sauzal Harbors, respectively). Significant $(p \leq 0.001)$ positive correlations were also found between \%GS and a number of trace metals for Ensenada $\left(\mathrm{Cd}_{\mathrm{pyr}}, \mathrm{CO}_{\mathrm{HCl}}\right.$, $\mathrm{Co}_{\text {pyr }}, \mathrm{Cu}_{\mathrm{pyr}}, \mathrm{Fe}_{\mathrm{HCl}}, \mathrm{Fe}_{\mathrm{pyr}}, \mathrm{Mn}_{\mathrm{HCl}}, \mathrm{Mn}_{\mathrm{pyr}}, \mathrm{Ni}_{\mathrm{pyr}}, \mathrm{Pb}_{\mathrm{HCl}}, \mathrm{Pb}_{\mathrm{pyr}}, \mathrm{Zn}_{\mathrm{HCl}}, \mathrm{Zn}_{\mathrm{pyr}}$ ) and El Sauzal $\left(\mathrm{Cd}_{\mathrm{HCl}}, \mathrm{Cd}_{\mathrm{pyr}}, \mathrm{Co}_{\mathrm{HCl}}, \mathrm{Co}_{\mathrm{pyr}}, \mathrm{Cu}_{\mathrm{pyr}}, \mathrm{Fe}_{\mathrm{HCl}}, \mathrm{Fe}_{\mathrm{pyr}}, \mathrm{Mn}_{\mathrm{HCl}}, \mathrm{Mn}_{\mathrm{pyr}}\right.$, $\mathrm{Ni}_{\mathrm{HCl}}, \mathrm{Pb}_{\mathrm{HCl}}, \mathrm{Pb}_{\mathrm{pyr}}, \mathrm{Zn}_{\mathrm{HCl}}, \mathrm{Zn}_{\mathrm{pyr}}$ ) Harbors (Table S3), suggesting that grain size is an important factor controlling the concentrations of these metals. Furthermore, the highly significant correlations $(p \leq 0.001)$ found between $C_{\text {org }}$ and a number of trace elements (Table S3) suggest that organic matter diagenetic processes also play an important role in controlling the behavior of several metals in Ensenada $\left(\mathrm{Cd}_{\mathrm{pyr}}, \mathrm{Co}_{\mathrm{HCl}}\right.$, $\left.\mathrm{Co}_{\text {pyr }}, \mathrm{Cu}_{\text {pyr }}, \mathrm{Fe}_{\mathrm{HCl}}, \mathrm{Mn}_{\mathrm{HCl}}, \mathrm{Mn}_{\mathrm{pyr}}, \mathrm{Ni}_{\mathrm{pyr}}, \mathrm{Pb}_{\mathrm{HCl}}, \mathrm{Pb}_{\text {pyr }}, \mathrm{Zn}_{\mathrm{HCl}}, \mathrm{Zn}_{\text {pyr }}\right)$ and $\mathrm{El}$ Sauzal $\left(\mathrm{Cd}_{\mathrm{HCl}}, \mathrm{Cd}_{\mathrm{pyr}}, \mathrm{Co}_{\mathrm{HCl}}, \mathrm{Co}_{\mathrm{pyr}}, \mathrm{Cu}_{\mathrm{pyr}}, \mathrm{Fe}_{\mathrm{HCl}}, \mathrm{Fe}_{\mathrm{pyr}}, \mathrm{Mn}_{\mathrm{HCl}}, \mathrm{Mn}_{\mathrm{pyr}}, \mathrm{Ni}_{\mathrm{HCl}}\right.$, $\left.\mathrm{Pb}_{\mathrm{HCl}}, \mathrm{Zn}_{\mathrm{HCl}}, \mathrm{Zn}_{\mathrm{pyr}}\right)$ Harbors.

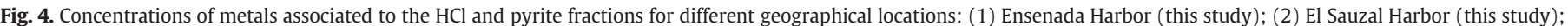

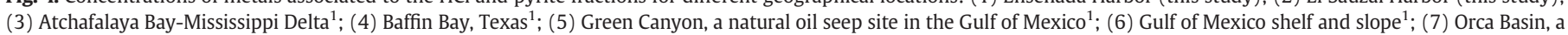

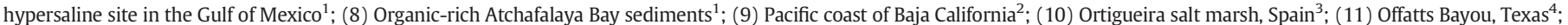

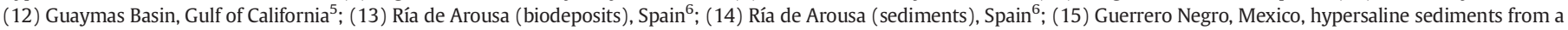

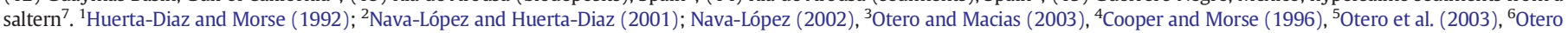
et al. (2005), ${ }^{7}$ Huerta-Diaz et al. (2011). 

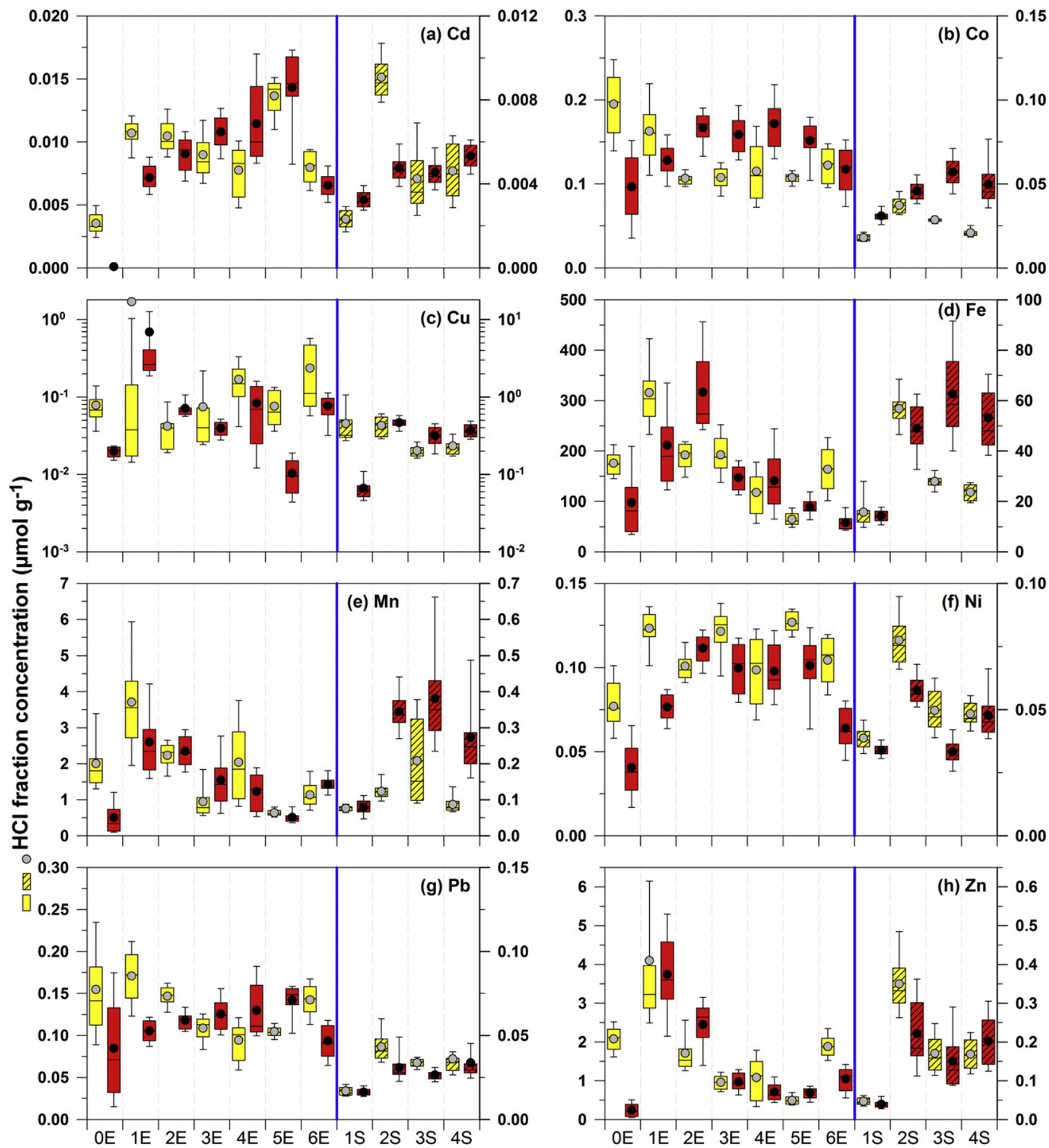

10

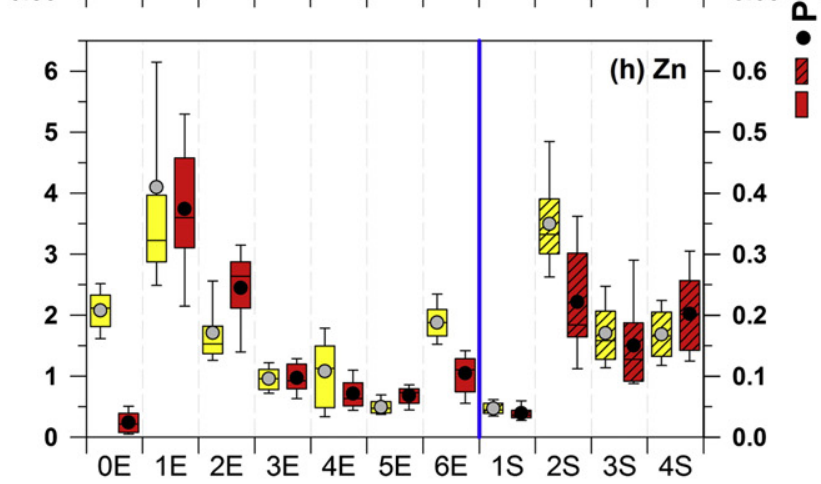

Cores

Cores

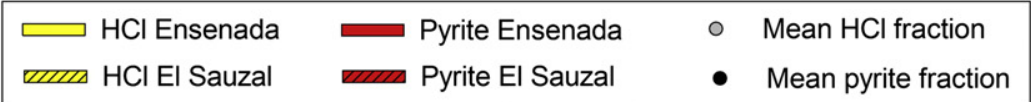

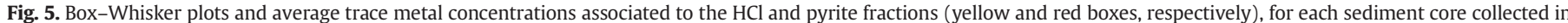
Ensenada and El Sauzal harbors (plain and dashed boxes, respectively). Concentrations below the detection limit in core 0 E were not considered for the calculation of basic statistics.

Average percentages of the reactive fraction with respect to total metal concentrations (the latter measured by Huerta-Diaz et al., 2008) were calculated for each sediment core in both harbors to assess the relative contribution of the reactive trace metals. Results, shown in Table 1, indicate that the highest percentage contributions in Ensenada harbor generally corresponded to cores $\mathrm{OE}, 1 \mathrm{E}$ and $5 \mathrm{E}$, whereas core $2 \mathrm{~S}$ was the one presenting the highest percentages in El Sauzal harbor. Assuming that the differences between total and reactive trace metal concentrations corresponded to the silicate fraction, which can be considered as unreactive towards the biota or during the processes of early diagenesis, then our results imply that the amounts of reactive trace metals potentially available for the biota are, in some cases, 


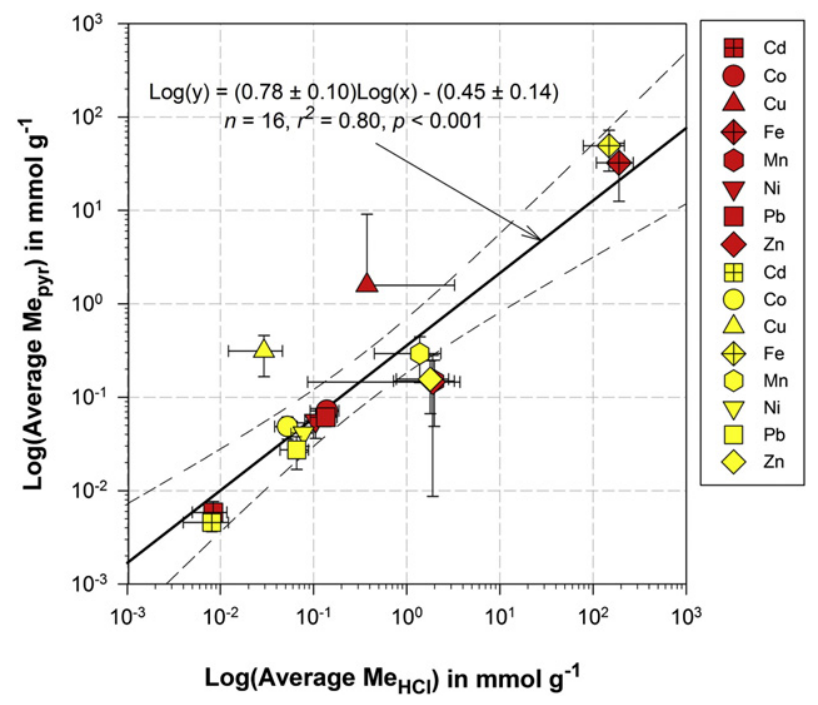

Fig. 6. Relationship between average concentrations ( \pm one standard deviation) of metals associated to the $\mathrm{HCl}$ fraction $\left(\mathrm{Me}_{\mathrm{HCl}}\right)$ and those associated to the pyrite fraction $\left(\mathrm{Me}_{\mathrm{pyr}}\right)$ for all combined sediment cores from Ensenada (red symbols) and El Sauzal (yellow symbols) harbors. Linear regression analysis and its 95\% confidence level are represented by the black continuous and dashed lines, respectively. Note the logarithmic scale on both axes. Metal concentrations below the detection limit and outliers were not considered for the calculation of basic statistics.

considerably higher in these four cores. For example, $90 \pm 13 \%$ of the total $\mathrm{Cd}$ concentration in core $5 \mathrm{E}$ is associated to the reactive fraction, but only $31 \pm 3 \%$ in core $2 \mathrm{E}$ (highest:lowest ratio of 2.9 ; Table 1 ). Similar results were obtained for $\mathrm{Ni}(40 \pm 5$ vs. $5 \pm 1), \mathrm{Cu}$ (70 \pm 12 vs. $21 \pm 3$ ), $\operatorname{Mn}(31 \pm 8$ vs. $10 \pm 1)$ and Co ( $35 \pm 3$ vs. $14 \pm 4)$, with highest:lowest ratios of $8.0,3.3,3.1$ and 2.5 , respectively.

As mentioned in the Introduction, dredging activities represent a net export of sediments (and associated trace metals) out of a harbor. Particularly important is the remobilization of metals produced by these dredging activities (e.g., Machado et al., 2011; Fathollahzadeh et al., 2015), especially when reduced sediments (like the ones present in our two harbors) are placed under oxic conditions (e.g., Morgan et al., 2012; Naylor et al., 2012). In this sense, the concentrations of the reactive fraction can be advantageously used to calculate the amounts of trace elements that can be potentially exported out of our two harbors.
Due to their lability, reactive metals can become readily available to the biota once the dredged sediments are discharged into their final destination, especially when pyrite is present, since this important diagenetic mineral is thermodynamically unstable under oxic conditions (Schoonen et al., 2000; Gartman and Luther, 2014) and acts as an important sink for a number of metals in aquatic ecosystems (Huerta-Diaz and Morse, 1992).

Hence, the amounts of trace metals associated with the pyrite or the reactive $\left(\mathrm{Me}_{\mathrm{HCl}}+\mathrm{Me}_{\mathrm{pyr}}\right)$ fractions that can be exported out of the two harbors can be calculated by: (1) using the average concentrations of these two fractions, (2) knowing the volume of sediments dredged from the two harbors, and (3) assuming a bulk sediment density of $2.6 \mathrm{~g} \mathrm{~cm}^{-3}$. It has been calculated that the amount of sediment that needs to be dredged from El Sauzal Harbor as part of its modernization plans will imply the removal of $300,000 \mathrm{~m}^{3}$ of sediments (API, 2010), whereas for the Ensenada Harbor the amounts of sediment that have been dredged at different times ranged from 150,000 (Romero-VargasMárquez, 1995) to $1,700,000 \mathrm{~m}^{3}$ (API, 1999). The results of these calculations (Table 2) indicate that the amounts of certain trace metals involved can be considerable: if $300,000 \mathrm{~m}^{3}$ of sediments were to be dredged from El Sauzal Harbor, then the amounts of trace metals associated to pyrite that can potentially be remobilized will range from $0.41 \pm 0.08$ to $15.8 \pm 7.4$ metric tons $(\mathrm{mt})$ for $\mathrm{Cd}$ and $\mathrm{Cu}$, respectively, in addition to $(2.2 \pm 1.0) \times 10^{3} \mathrm{mt}$ of Fe-pyrite. The mass of trace metals associated with pyrite that were exported out of Ensenada Harbor through the dredging of $150,000 \mathrm{~m}^{3}$ ranged from $0.20 \pm 0.13$ to $26 \pm 49 \mathrm{mt}$ for Cd and $\mathrm{Cu}$, respectively, plus $(0.72 \pm 0.44) \times 10^{3} \mathrm{mt}$ of Fe-pyrite (Table 2). When $1,700,000 \mathrm{~m}^{3}$ of sediments were dredged, the masses of trace metals exported out of the Ensenada Harbor ranged from $2.3 \pm 1.5$ to $(0.30 \pm 0.56) \times 10^{3} \mathrm{mt}$ of $\mathrm{Cd}$ and $\mathrm{Cu}$, respectively, and $(8.2 \pm$ $5.0) \times 10^{3}$ metric tons of Fe-pyrite (Table 2). Considering the same volumes of dredged sediments and assuming that all the reactive fraction will be remobilized once the dredged sediments are deposited in its final destination, then the masses of trace metals exported out of the harbors will increase considerably (Table 2): $1.1 \pm 0.4$ to $100 \pm 56 \mathrm{mt}$ for $\mathrm{Cd}$ and $\mathrm{Zn}$, respectively, in addition to $(8.6 \pm 3.5) \times 10^{3} \mathrm{mt}$ of reactive Fe for El Sauzal Harbor; $0.56 \pm 0.25$ to $50 \pm 30 \mathrm{mt}$ for $\mathrm{Cd}$ and $\mathrm{Zn}$, respectively, plus $(4.8 \pm 1.9) \times 10^{3} \mathrm{mt}$ of reactive Fe for Ensenada Harbor $\left(150,000 \mathrm{~m}^{3}\right.$ of dredged sediments); and $6.4 \pm 2.9$ to $(0.56 \pm 0.34) \times 10^{3} \mathrm{mt}$ of $\mathrm{Cd}$ and $\mathrm{Zn}$, respectively, in addition to $(55 \pm 22) \times 10^{3} \mathrm{mt}$ of reactive $\mathrm{Fe}\left(1,700,000 \mathrm{~m}^{3}\right.$ of dredged sediments). These results suggest that $\mathrm{Fe}, \mathrm{Zn}, \mathrm{Cu}, \mathrm{Mn}$ and $\mathrm{Pb}$ are the most remobilized labile metals and, therefore, the most bioavailable (Table 2) in both harbors. Hence, dredging of these harbors would most probably cause

Table 1

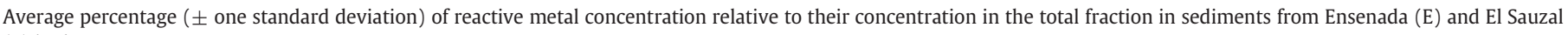
(S) harbo;rs.

\begin{tabular}{|c|c|c|c|c|c|c|c|c|c|}
\hline Core & $\mathrm{Cd}$ & Co & $\mathrm{Cu}$ & $\mathrm{Fe}$ & $\mathrm{Mn}$ & $\mathrm{Ni}$ & $\mathrm{Pb}$ & $\mathrm{Zn}$ & Overall \\
\hline & \multicolumn{9}{|c|}{ Ensenada Harbor } \\
\hline OE (43) & $70 \pm 36$ & $14 \pm 4$ & $21 \pm 3$ & $15 \pm 2$ & $22 \pm 8$ & $5 \pm 1$ & $84 \pm 29$ & $93 \pm 35$ & $41 \pm 36$ \\
\hline $1 \mathrm{E}(32)$ & $36 \pm 4$ & $19 \pm 3$ & $57 \pm 31$ & $27 \pm 4$ & $31 \pm 8$ & $18 \pm 2$ & $62 \pm 13$ & $78 \pm 16$ & $41 \pm 22$ \\
\hline $2 \mathrm{E}(27)$ & $31 \pm 3$ & $19 \pm 1$ & $69 \pm 5^{*}$ & $21 \pm 2$ & $20 \pm 2$ & $19 \pm 2$ & $58 \pm 4$ & $57 \pm 9^{*}$ & $37 \pm 21$ \\
\hline $3 E(32)$ & $44 \pm 6$ & $26 \pm 3$ & $60 \pm 7$ & $24 \pm 5$ & $12 \pm 5$ & $32 \pm 4$ & $59 \pm 5$ & $61 \pm 7$ & $40 \pm 19$ \\
\hline $4 \mathrm{E}(21)$ & $38 \pm 5$ & $24 \pm 3$ & $67 \pm 11$ & $16 \pm 5$ & $19 \pm 7$ & $25 \pm 2$ & $57 \pm 8$ & $56 \pm 15$ & $38 \pm 20$ \\
\hline $5 \mathrm{E}(14)$ & $90 \pm 13$ & $35 \pm 3$ & $70 \pm 12$ & $15 \pm 3$ & $10 \pm 1$ & $40 \pm 5$ & $69 \pm 6$ & $62 \pm 4$ & $49 \pm 28$ \\
\hline $6 \mathrm{E}(9)$ & $31 \pm 4$ & $20 \pm 3$ & $57 \pm 5$ & $15 \pm 4$ & $15 \pm 4$ & $22 \pm 3$ & $51 \pm 7$ & $73 \pm 9$ & $35 \pm 22$ \\
\hline \multirow[t]{2}{*}{ Overall (182) } & $49 \pm 22$ & $22 \pm 7$ & $57 \pm 17$ & $19 \pm 5$ & $18 \pm 7$ & $23 \pm 11$ & $64 \pm 13$ & $69 \pm 13$ & $40 \pm 22$ \\
\hline & \multicolumn{9}{|c|}{ El Sauzal Harbor } \\
\hline 1S (13) & $37 \pm 5$ & $19 \pm 1$ & $44 \pm 8$ & $19 \pm 6$ & $16 \pm 1$ & $25 \pm 1$ & $39 \pm 7$ & $38 \pm 6$ & $30 \pm 11$ \\
\hline $2 \mathrm{~S}(13)$ & $71 \pm 9$ & $28 \pm 4$ & $41 \pm 5$ & $58 \pm 6$ & $26 \pm 4$ & $36 \pm 4$ & $65 \pm 15$ & $79 \pm 14$ & $50 \pm 20$ \\
\hline $3 S(29)$ & $48 \pm 8$ & $23 \pm 2$ & $48 \pm 6$ & $30 \pm 3$ & $31 \pm 10$ & $24 \pm 2$ & $59 \pm 9$ & $63 \pm 8$ & $41 \pm 16$ \\
\hline $4 S(19)$ & $55 \pm 5$ & $20 \pm 2$ & $53 \pm 7$ & $30 \pm 3$ & $17 \pm 3$ & $33 \pm 2$ & $69 \pm 27$ & $60 \pm 8$ & $42 \pm 19$ \\
\hline Overall (74) & $53 \pm 14$ & $23 \pm 4$ & $46 \pm 5$ & $35 \pm 17$ & $23 \pm 7$ & $30 \pm 6$ & $58 \pm 13$ & $60 \pm 17$ & $41 \pm 15$ \\
\hline
\end{tabular}

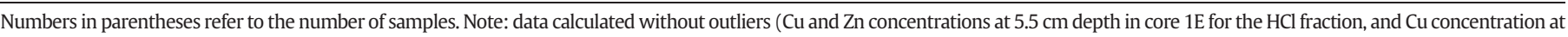
$14.5 \mathrm{~cm}$ in core $1 \mathrm{E}$ for the $\mathrm{HCl}$ and pyrite fractions). 
Table 2

Average ( \pm one standard deviation) mass of trace metals that can potentially be exported out of El Sauzal and Ensenada harbors due to dredging activities. It was assumed that only metals associated to the pyrite and reactive fractions could be remobilized during these activities. For transformation of volume to mass, sediment density was assumed to be $2.6 \mathrm{~g} \mathrm{~cm}^{-3}$. The volumes of dredged sediments used in these calculations were $300,000 \mathrm{~m}^{3}$ for El Sauzal Harbor (API, 2010), and 150,000 (Romero-Vargas-Márquez, 1995) to $1,700,000 \mathrm{~m}^{3}$ (API, 1999) for Ensenada Harbor. Data calculated without outliers: Cu and Zn concentrations at $5.5 \mathrm{~cm}$ depth in core $1 \mathrm{E}$ for the $\mathrm{HCl}$ fraction, and $\mathrm{Cu}$ concentrations at $14.5 \mathrm{~cm}$ in core $1 \mathrm{E}$ for the $\mathrm{HCl}$ and pyrite fractions.

\begin{tabular}{llll}
\hline \multirow{2}{*}{ Element } & \multicolumn{2}{l}{ Average mass of exported trace metal (metric tons) } \\
\cline { 2 - 4 } & $\begin{array}{l}\text { El Sauzal Harbor } \\
\left(300,000 \mathrm{~m}^{3}\right)\end{array}$ & $\begin{array}{l}\text { Ensenada Harbor } \\
\left(150,000 \mathrm{~m}^{3}\right)\end{array}$ & $\begin{array}{l}\text { Ensenada Harbor } \\
\left(1,700,000 \mathrm{~m}^{3}\right)\end{array}$ \\
\hline Pyrite fraction & & \\
$\mathrm{Cd}$ & $0.41 \pm 0.08$ & $0.20 \pm 0.13$ & $2.3 \pm 1.5$ \\
$\mathrm{Co}$ & $2.3 \pm 0.6$ & $1.6 \pm 0.5$ & $18.4 \pm 5.3$ \\
$\mathrm{Cu}$ & $15.8 \pm 7.4$ & $26 \pm 49$ & $(0.30 \pm 0.56) \times 10^{3}$ \\
$\mathrm{Fe}$ & $(2.2 \pm 1.0) \times 10^{3}$ & $(0.72 \pm 0.44) \times 10^{3}$ & $(8.2 \pm 5.0) \times 10^{3}$ \\
$\mathrm{Mn}$ & $12.8 \pm 6.6$ & $3.2 \pm 2.2$ & $37 \pm 25$ \\
$\mathrm{Ni}$ & $7.8 \pm 9.2$ & $1.3 \pm 0.5$ & $14.4 \pm 5.2$ \\
$\mathrm{~Pb}$ & $1.3 \pm 0.5$ & $4.6 \pm 1.5$ & $52 \pm 17$ \\
$\mathrm{Zn}$ & $8.1 \pm 4.7$ & $3.8 \pm 3.6$ & $43 \pm 40$ \\
& & & \\
Reactive fraction & & $6.4 \pm 2.9$ \\
$\mathrm{Cd}$ & $1.1 \pm 0.4$ & $0.56 \pm 0.25$ & $54 \pm 10$ \\
$\mathrm{Co}$ & $4.6 \pm 1.0$ & $4.8 \pm 0.9$ & $(0.32 \pm 0.56) \times 10^{3}$ \\
$\mathrm{Cu}$ & $16.9 \pm 7.1$ & $28 \pm 50$ & $(55 \pm 22) \times 10^{3}$ \\
$\mathrm{Fe}$ & $(8.6 \pm 3.5) \times 10^{3}$ & $(4.8 \pm 1.9) \times 10^{3}$ & $(0.52 \pm 0.32) \times 10^{3}$ \\
$\mathrm{Mn}$ & $72 \pm 42$ & $46 \pm 28$ & $41.4 \pm 9.9$ \\
$\mathrm{Ni}$ & $5.5 \pm 1.4$ & $3.6 \pm 0.9$ & $175 \pm 36$ \\
$\mathrm{~Pb}$ & $15.1 \pm 5.1$ & $15.5 \pm 3.2$ & $(0.56 \pm 0.34) \times 10^{3}$ \\
$\mathrm{Zn}$ & $100 \pm 56$ & $50 \pm 30$ & \\
\hline
\end{tabular}

hazardous effects on benthic organisms, especially if the dredged sediments come from the inner part of Ensenada Harbor or from the west corner of El Sauzal Harbor, given the high concentrations of these metals in the reactive fraction of these sediments.

\subsection{DOP, DOS and DTMP in both harbors}

Average degrees of pyritization (DOP) of the sediments from Ensenada and El Sauzal Harbors were lower than expected $(15.1 \pm 7.4$ and $25.2 \pm 8.7 \%$, respectively; Fig. 7) considering that, generally, the sediments of the two harbors are anoxic close to the sediment-water interface. The reason for these relatively low DOP values is that considerable portions of the sedimentary Fe sulfides are in the form of AVS, with average concentrations for the Ensenada and El Sauzal Harbors of $83 \pm$ 71 and $51 \pm 23 \mu \mathrm{mol} \mathrm{g}^{-1}$, respectively (Table S2). Interestingly, AVS concentrations were, in some instances (e.g., cores 1E, 3E, OE and 2S), higher than those obtained for pyrite, as reflected in their corresponding average pyrite/AVS molar ratios $(0.30 \pm 0.16,0.9 \pm 1.6,0.23 \pm 0.13$ and $0.78 \pm 0.15$, respectively). The high sedimentary AVS concentrations, however, produce high DOS values for both Ensenada and El Sauzal Harbors ( $49 \pm 23$ and $51 \pm 16 \%$, respectively) indicating that approximately half of the solid reactive Fe is bound to sulfide and that iron sulfide production in these harbors is not limited by the availability of $\mathrm{Fe}_{\mathrm{HCl}}$.

Average degrees of trace metal pyritization (DTMP) for Ensenada Harbor $(n=182)$ followed the order $\mathrm{Zn}(7.9 \pm 5.0 \%) \approx \mathrm{Mn}(8.1 \pm$ $5.3 \%)<\mathrm{Fe}(15.1 \pm 7.4 \%)<\mathrm{Cd}(29 \pm 18 \%) \approx \mathrm{Pb}(30 \pm 11 \%)<\mathrm{Ni}$ $(33.3 \pm 8.4 \%) \approx \mathrm{Co}(35 \pm 12 \%) \ll \mathrm{Cu}(81 \pm 18 \%)$, with El Sauzal Harbor $(n=74)$ showing a similar order: $\mathrm{Zn}(8.1 \pm 2.2 \%)<\mathrm{Mn}(19.3 \pm$ $8.7 \%)<\mathrm{Fe}(25.2 \pm 8.7 \%)<\mathrm{Pb}(29.5 \pm 3.6 \%)<\mathrm{Ni}(35.3 \pm 8.1 \%)<\mathrm{Cd}$ $(38.9 \pm 8.9 \%)<\mathrm{Co}(48.1 \pm 6.5 \%) \ll \mathrm{Cu}(88 \pm 14 \%)$. Overall, the least and most pyritized trace metals for both harbors were $\mathrm{Zn}$ and $\mathrm{Cu}$, respectively (Fig. 7). Among the two harbors (Fig. 7), the least pyritized sediment for $\mathrm{Zn}$ was core $\mathrm{OE}(1.17 \pm 0.86, n=43)$ whereas the sediments most pyritized for $\mathrm{Cu}$ were cores $1 \mathrm{E}(93 \pm 16, n=30), 2 \mathrm{E}$
(94.1 \pm 3.7, $n=27)$, 3S (93.6 $\pm 1.9, n=29)$ and 4 S (93.8 \pm 2.3 , $n=19)$. Our results were in general agreement with those obtained by Nava-López and Huerta-Diaz (2001) and Huerta-Diaz and Morse (1992) for sediments of the Mexican Pacific and the Gulf of Mexico, respectively, who reported that $\mathrm{Zn}$ was not pyritized to a great extent (0-20\%) whereas Cu tended to have moderate to high DTMP values (10-100\%). Cadmium, a metal that is usually not pyritized to a great extent, however, showed a relatively high percentage of DTMP (29 \pm $18 \%$ to $38.9 \pm 8.9 \%$ ), probably due to its abundance in our coastal sediments as a consequence of the abnormally high $\mathrm{Cd}$ concentrations that have been measured in plankton from Baja California (10-20 ppm; Martin and Broenkow, 1975) and the contribution of this element by upwelling processes (Segovia-Zavala et al., 1998) that are common in the northwest coast of Baja California during spring and summer (Alvarez-Borrego and Alvarez-Borrego, 1982; Muñoz-Barbosa et al., 2004). Our analyzed elements were arbitrarily grouped into three different levels of association with pyrite based on their DTMP values: Group DTMP-1 which includes only Cu, the most extensively pyritized metal; Group DTMP-2 that comprises those elements that showed intermediate DTMP levels (29-48\%), namely Cd, Co, Ni and Pb; and Group DTMP-3 which includes trace metals that were weakly pyritized ( $\mathrm{Mn}$ and $\mathrm{Zn}$ ). However, and independently of the group to which they belonged, DOP values showed highly significant ( $p \leq 0.001, n=254-$ 256) linear correlations with the different DTMP values (Fig. 8). Considering that the steeper the slope is, the more readily the element is pyritized, then the order in which the elements were increasingly pyritized in the sediments of both harbors was (Fig. 8): Zn (0.19 \pm $0.03)<\mathrm{Pb}(0.27 \pm 0.07)<\mathrm{Ni}(0.37 \pm 0.05) \approx \mathrm{Cu}(0.39 \pm 0.12)<\mathrm{Mn}$ $(0.49 \pm 0.05)<\mathrm{Cd}(0.78 \pm 0.10)<\mathrm{Co}(0.94 \pm 0.06)$. These results indicate that for each increase in one percentage point of DOP, the DTMP-Zn increased by only $0.19 \pm 0.03 \%$, whereas in the case of Co for each increase in one percentage point of DOP, the DTMP-Co increased by as much as $0.94 \pm 0.06 \%$.

It is interesting to note that the elements that were highly pyritized (Co and, especially, $\mathrm{Cu}$ ) were not necessarily highly enriched in the sediments (as expressed by their enrichment factor, or $\mathrm{EF}_{\mathrm{Me}}$ ). For example, according to Huerta-Diaz et al. (2008), Cu was neither enriched nor impoverished $\left(0.6>\mathrm{EF}_{\mathrm{Cu}}>1.5\right)$ in both harbors, whereas $\mathrm{Zn}$ was considered as slightly enriched $\left(1.5>\mathrm{EF}_{\mathrm{Zn}}>2.5\right)$. What factors determine the degree of association of trace metals with sedimentary pyrite? According to our results, the relative abundance of the metals associated with the $\mathrm{HCl}$ fraction (e.g., Fig. 6) is one factor. Another factor, however, can be ascribed to metal class-type behavior combined with the solubility product of the different metal sulfides (Huerta-Diaz and Morse, 1992). The free metal ion $\left(\mathrm{Me}^{2+}\right)$ concentration in equilibrium with a homogeneous metal sulfide (Stumm and Morgan, 1996) is governed by the following reaction (Jacobs, 1984):

$\mathrm{H}^{+}+\mathrm{MeS}_{(\mathrm{s})} \rightarrow \mathrm{Me}^{2+}+\mathrm{HS}^{-}$

and that of Fe by:

$\mathrm{H}^{+}+\mathrm{FeS}_{2(\mathrm{~s})} \rightarrow \mathrm{Fe}^{2+}+\mathrm{HS}^{-}+\mathrm{S}^{0}$

where $\mathrm{MeS}_{(\mathrm{s})}$ represents the solid sulfide trace metal. Solid solution formation may be characterized by the following reaction (Stumm and Morgan, 1996):

$\mathrm{FeS}_{2(\mathrm{~s})}+\mathrm{Me}^{2+} \rightarrow \mathrm{MeS}_{(\mathrm{s})}+\mathrm{Fe}^{2+}+\mathrm{S}^{0}$

It can be demonstrated that the equilibrium constant for reaction (7) corresponds to the ratio of the solubility product constants $\mathrm{K}_{\mathrm{sp}(\mathrm{MeS})}$ and $\mathrm{K}_{\mathrm{sp} \text { (pyr) }}$ of Eqs. (5) and (6). Eqs. (5) to (7) suggest that there should be a relationship between DTMP (a proxy to solid solution activity) and the ratio $\mathrm{K}_{\mathrm{sp}(\mathrm{Mes})} / \mathrm{K}_{\mathrm{sp}(\mathrm{pyr})}$; we found that this could indeed be the case. 

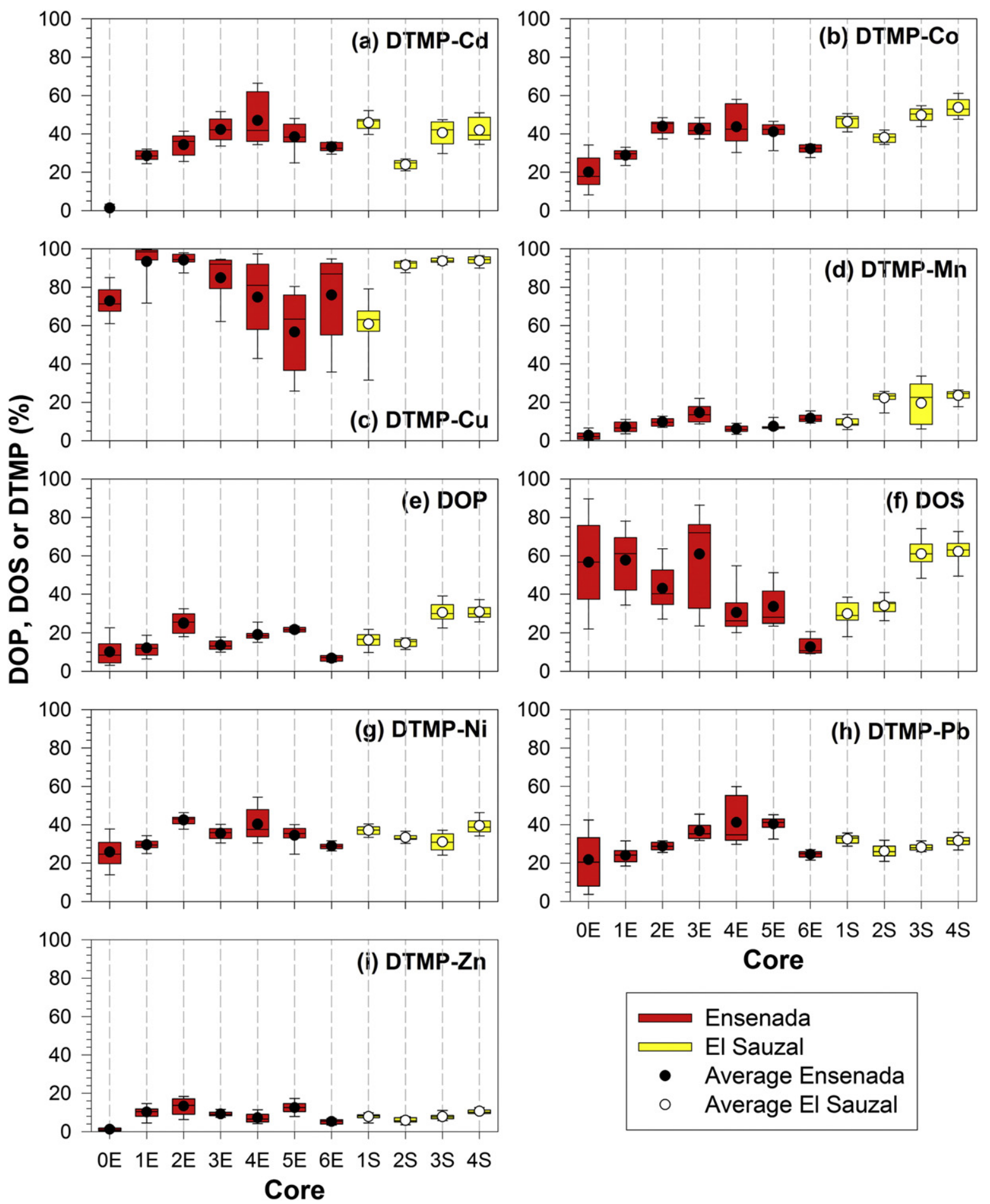

Core

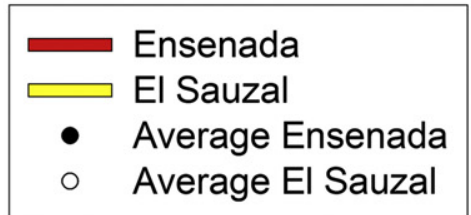

Core

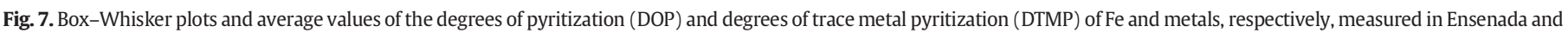

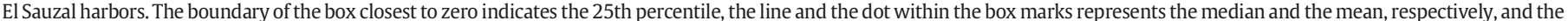

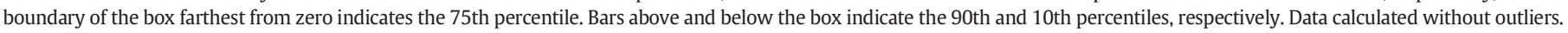

When our average DTMP values for each of the two harbors were plotted against the $-\log \left(\mathrm{K}_{\mathrm{sp}(\mathrm{MeS})} / \mathrm{K}_{\mathrm{sp}(\mathrm{pyr})}\right)$ for the different trace metals, significant correlations were found for both Ensenada $\left(p \leq 0.01, r^{2}=0.73\right.$, $n=8)$ and El Sauzal ( $\left.p \leq 0.05, r^{2}=0.57, n=8\right)$ Harbors (Fig. 9). Hence, the incorporation of trace metals into the pyrite phase and solid solution formation with this mineral phase is, most probably, influenced by the solubility products of the metal sulfide complexes, and, therefore, by the equilibrium reached in reaction (7).

\subsection{Fluxes of dissolved $\mathrm{Fe}^{2+}$ in Ensenada Harbor}

To explain the mechanisms that influence pyrite and AVS formation in the sediments of Ensenada Harbor, dissolved sulfate and dissolved $\mathrm{Fe}^{2+}$ were measured in sediment pore waters from core 0E. Fig. 10a clearly illustrates the processes involved in Fe sulfide formation, where sulfate concentrations decrease with depth due to bacterial sulfate reduction processes until, at a depth of $40 \mathrm{~cm}$, sulfate is completely 

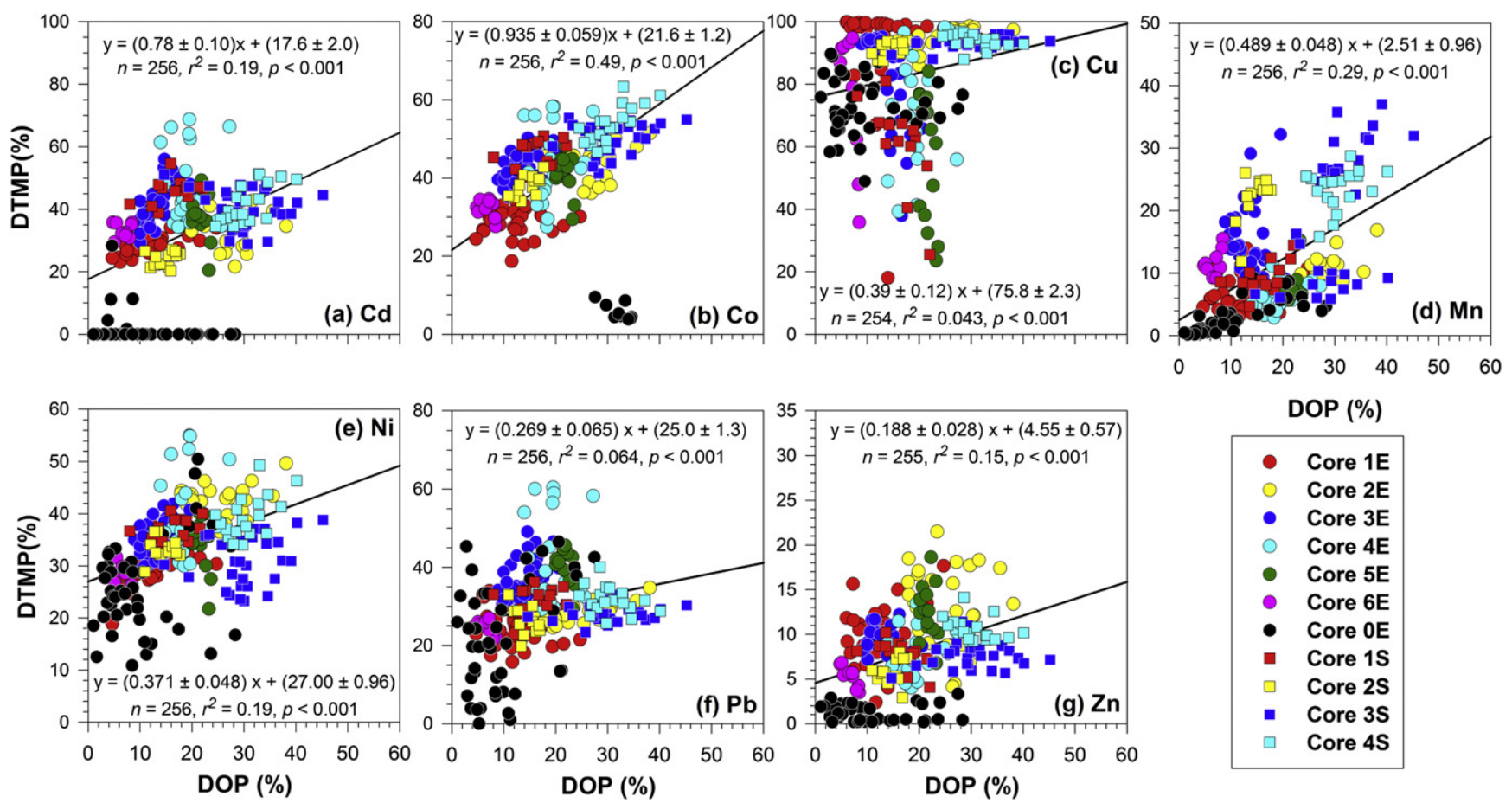

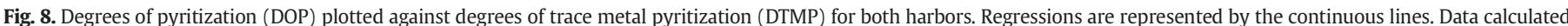
without outliers.

depleted from pore water. The $\mathrm{H}_{2} \mathrm{~S}$ produced by the process of sulfate reduction titrates the dissolved $\mathrm{Fe}^{2+}$ that originated from the reductive dissolution of iron oxyhydroxides, forming in the process Fe sulfides in the form of pyrite and AVS. The titration of $\mathrm{Fe}^{2+}$ continues until there is no more $\mathrm{H}_{2} \mathrm{~S}$ available due to the complete depletion of $\mathrm{SO}_{4}^{2-}$ through the process of sulfate reduction, at which point $(39 \mathrm{~cm})$ the concentration of $\mathrm{Fe}^{2+}$ increases again. The Fe sulfide (pyrite + AVS) profile is then essentially the mirror image of the $\mathrm{Fe}^{2+}$ profile, with high concentrations of the former corresponding to low concentrations of the latter (Fig. 10a). According to this figure, once there is no more sulfate available for its bacterial reduction to $\mathrm{H}_{2} \mathrm{~S}$ (at $40 \mathrm{~cm}$ depth), $\mathrm{Fe}^{2+}$ cannot continue

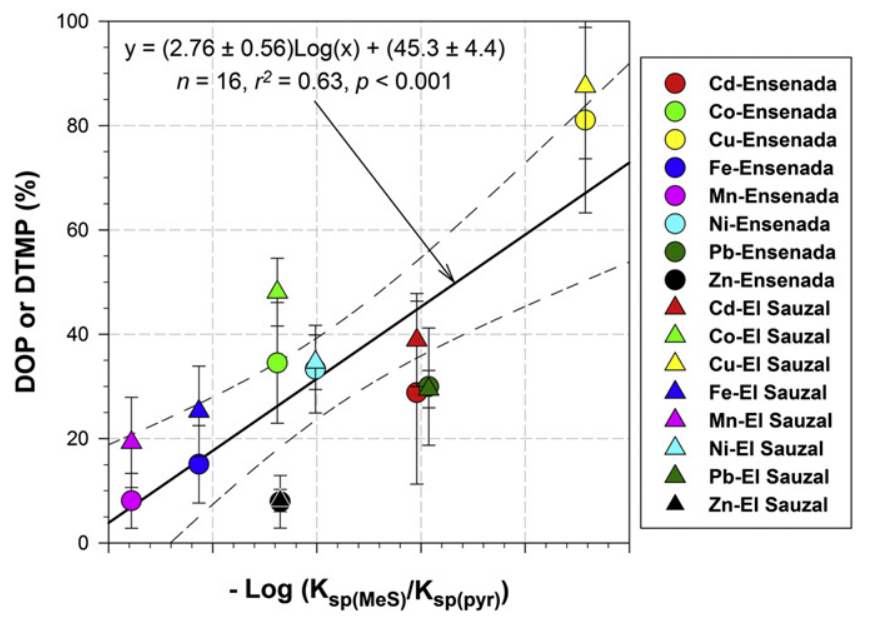

Fig. 9. Average ( \pm one standard deviation) degrees of trace metal pyritization (DTMP) plotted against metal sulfide $\left(\mathrm{K}_{\mathrm{sp}(\mathrm{Mes})}\right)$ to pyrite $\left(\mathrm{K}_{\mathrm{sp}(\mathrm{pyr})}\right)$ solubility product ratios for (a) Ensenada and (b) El Sauzal harbors. Solubility product constants were taken from DiToro et al. (1990) and Rickard (2012). to be precipitated as sulfide and Fe sulfide concentrations start to decrease.

Dissolved iron fluxes $(\mathrm{F})$, which indicate the rate of formation of $\mathrm{Fe}$ sulfides in the sediments, can be calculated from our measured $\mathrm{Fe}^{2+}$ concentrations (C) using the unidimensional form of Fick's First Law (Berner, 1980):

$\mathrm{F}=-\frac{\varphi \mathrm{D}_{0}}{\theta^{2}} \frac{\partial \mathrm{C}}{\partial \mathrm{x}}$

where $\varphi, \theta$, and $x$ represent porosity, tortuosity and depth of the sediment, respectively, in core $0 \mathrm{E}$. A value of $5.82 \times 10^{-6} \mathrm{~cm}^{2} \mathrm{~s}^{-1}$ at $18{ }^{\circ} \mathrm{C}$ (Li and Gregory, 1974) was used for the diffusion coefficient $\left(D_{0}\right)$. No $D_{0}$ corrections for viscosity were made since it has been calculated that diffusion coefficients of ions in water and in seawater differ by no more than zero to $8 \%$ (Li and Gregory, 1974). Porosity $(\varphi)$ was approximated from the percent of water of the sediment, whereas tortuosity $(\theta)$ was calculated from the expression $\theta^{2}=1-\ln \left(\varphi^{2}\right)$ developed by Boudreau (1996). Fluxes towards the water column and towards the sediment were considered as negative and positive, respectively. The results of this exercise are shown in Fig. 10b, where, as expected, the upper portion of the core shows an $\mathrm{Fe}^{2+}$ flux of $0.90 \mathrm{~mol} \mathrm{~m} \mathrm{y}^{-2} \mathrm{y}^{-1}$ towards the sediment, whereas the deeper portions of the sediment show fluxes of 0.69 and $0.55 \mathrm{~mol} \mathrm{~m}^{-2} \mathrm{y}^{-1}$ towards the water column. It should be noted, however, that the latter results should be taken with caution due to potential contamination of this part of the core during its handling. Hence, dissolved Fe fluxes of approximately the same magnitude converge in the middle portion of the core, which is the place where most of the Fe sulfides are actively forming and where $\mathrm{Fe}^{2+}$ fluxes approach values close to zero (Fig. $10 \mathrm{~b}$ ). Since dissolved $\mathrm{Fe}$ and $\mathrm{SO}_{4}^{2-}$ were measured only in core $\mathrm{OE}$, a harbor-wide $\mathrm{Fe}^{2+}$ flux calculation cannot be made. As a first approximation, however, we can assume that the behavior observed in core $\mathrm{OE}$ is similar to all of the sediments in Ensenada Harbor $\left(1.95 \mathrm{~km}^{2}\right.$ surface area). Under this assumption and using the upper core $\mathrm{Fe}^{2+}$ 


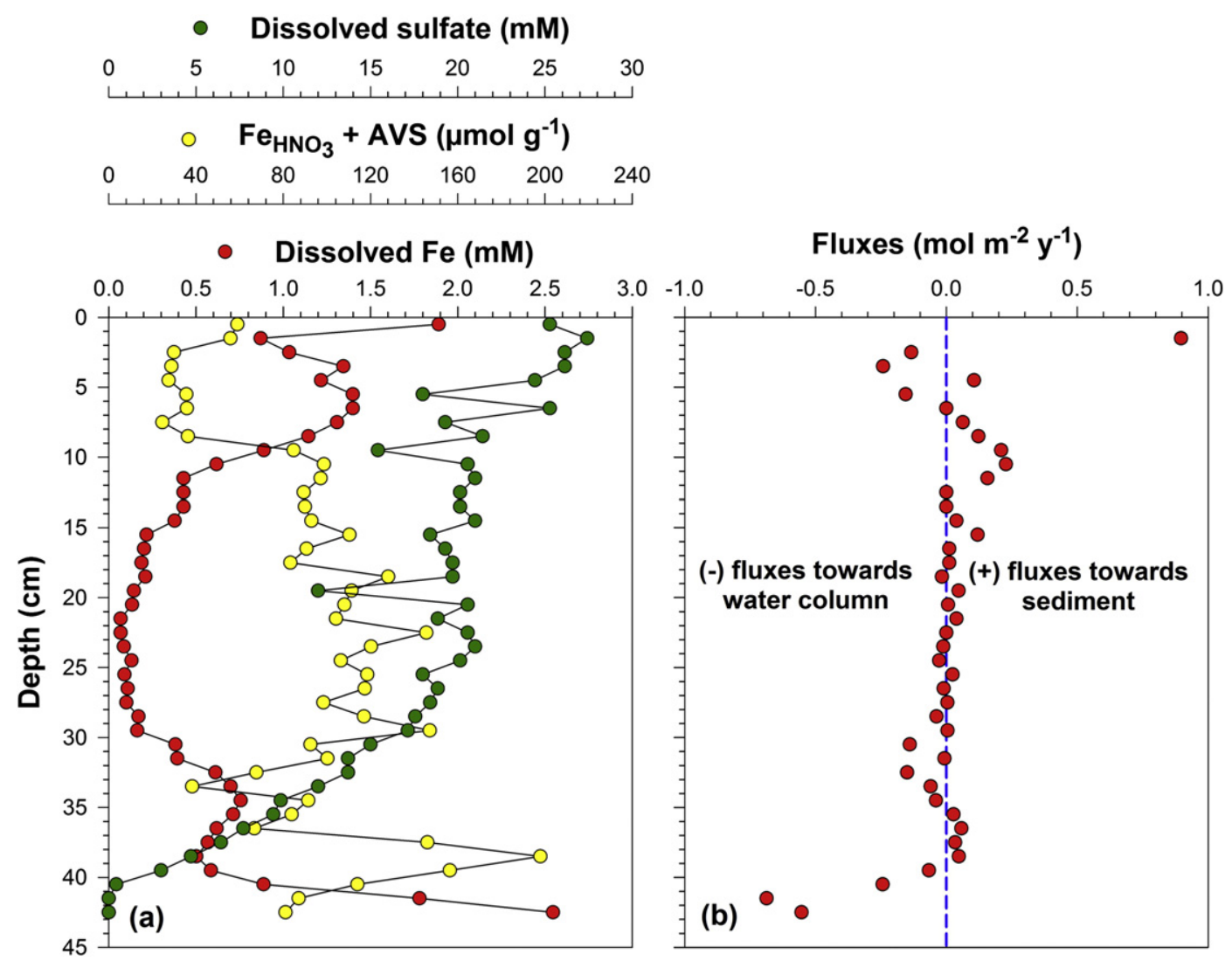

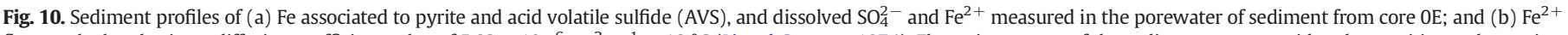

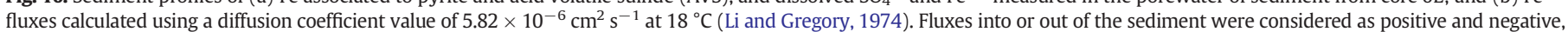
respectively. It should be noted that flux results for the deepest portion of the core should be taken with caution due to potential contamination during its handling.

flux of $0.90 \mathrm{~mol} \mathrm{~m}^{-2} \mathrm{y}^{-1}$ (Fig. 10b) we calculated that 98 metric tons of Fe are precipitated as Fe sulfides every year to Ensenada Harbor sediments. This amount of Fe (and associated trace metals) will remain preserved in the sediments, unless it is perturbed by processes such as dredging or sediment resuspension. It is interesting to note that the amount of Fe sulfides formed in the sediments represents only 1.2 to $14 \%$ of the Fe associated to pyrite that can be exported out of Ensenada Harbor through dredging (Table 2).

\subsection{Metal concentrations in the polychaete A. brevis collected from Ensenada Harbor}

In Ensenada Harbor, trace metal concentrations in the burrowing polychaete $A$. brevis differed somewhat among the 5 study sites, with mean values of $\mathrm{Cd}, \mathrm{Co}$ and $\mathrm{Ni}$ being highest at the site closest to the harbor mouth (5E), whereas those of $\mathrm{Cu}$ and $\mathrm{Pb}$ were highest at an inner harbor site (2E) as were those of $\mathrm{Zn}$ (site 1E) (Table 3). To compare overall metal-contamination levels at each site, we used the Metal Pollution Index (MPI), calculated as MPI $=\left(\mathrm{Cf}_{1} \times \mathrm{Cf}_{2} \times \ldots \mathrm{Cf}_{\mathrm{n}}\right)^{1 / \mathrm{n}}$ (Usero et al., 1996, 1997, 2005; Chaudhuri et al., 2007), where $C f_{n}$ is the concentration of the $n$ metal in the sample, to calculate the geometric mean value for each site (Varol, 2011). MPI values suggest that polychaetes at site $2 \mathrm{E}$ have the highest overall metal concentrations (Table 3).

The accumulation of sediment-associated metals by $A$. brevis can be further evaluated using the biota-sediment accumulation factor (BSAF) for metals (Burkhard, 2009), which is the ratio of total metal concentrations in this polychaete relative to those in the first $\mathrm{cm}$ of the sediments. Our calculated BSAF values using total sediment concentrations (as reported by Huerta-Diaz et al. (2008)) were: $0.13-0.44$ for Cd, 0.030.11 for $\mathrm{Co}, 0.23-2.2$ for $\mathrm{Cu}, 0.05-0.24$ for $\mathrm{Ni}, 0.05-0.08$ for $\mathrm{Pb}$ and $1.4-$ 5.3 for $\mathrm{Zn}$. BSAFs $>1$ were calculated for $\mathrm{Cu}$ in $A$. brevis collected from

Table 3

Average concentrations \pm 1 standard deviation and Metal Pollution Index (MPI) values for the burrowing opheliid polychaete Armandia brevis collected in Ensenada Harbor.

\begin{tabular}{|c|c|c|c|c|c|c|c|}
\hline \multirow{2}{*}{$\begin{array}{l}\text { Core } \\
\text { code }\end{array}$} & $\mathrm{Cd}$ & Co & $\mathrm{Cu}$ & $\mathrm{Ni}$ & $\mathrm{Pb}$ & $\mathrm{Zn}$ & MPI \\
\hline & \multicolumn{7}{|l|}{$\left(\mathrm{nmol} \mathrm{g}^{-1}\right)$} \\
\hline $1 \mathrm{E}(4,7)$ & $6.5 \pm 0.6$ & $44.2 \pm 8.8$ & $(1.13 \pm 0.18) \times 10^{3}$ & $47 \pm 13$ & $19.3 \pm 3.5$ & $(7.5 \pm 1.5) \times 10^{3}$ & 115 \\
\hline $2 \mathrm{E}(5,6)$ & $6.1 \pm 0.7$ & $29.2 \pm 6.7$ & $(2.67 \pm 0.40) \times 10^{3}$ & $99 \pm 59$ & $23.2 \pm 3.3$ & $(5.8 \pm 1.0) \times 10^{3}$ & 136 \\
\hline $3 \mathrm{E}(5,5)$ & $7.0 \pm 1.0$ & $42.6 \pm 8.5$ & $(1.18 \pm 0.26) \times 10^{3}$ & $57.4 \pm 6.3$ & $18.7 \pm 2.8$ & $(4.6 \pm 0.8) \times 10^{3}$ & 109 \\
\hline $4 \mathrm{E}(5,7)$ & $8.3 \pm 0.6$ & $47.7 \pm 3.8$ & $(0.70 \pm 0.13) \times 10^{3}$ & $70 \pm 23$ & $17.0 \pm 2.0$ & $(4.14 \pm 0.26) \times 10^{3}$ & 105 \\
\hline $5 \mathrm{E}(5,7)$ & $12.2 \pm 1.2$ & $56.1 \pm 4.8$ & $(0.546 \pm 0.083) \times 10^{3}$ & $127 \pm 14$ & $16.8 \pm 1.8$ & $(4.76 \pm 0.23) \times 10^{3}$ & 125 \\
\hline Overall & $8.0 \pm 2.5$ & $43.9 \pm 9.8$ & $(1.25 \pm 0.84) \times 10^{3}$ & $80 \pm 33$ & $19.0 \pm 2.6$ & $(5.4 \pm 1.4) \times 10^{3}$ & 124 \\
\hline
\end{tabular}

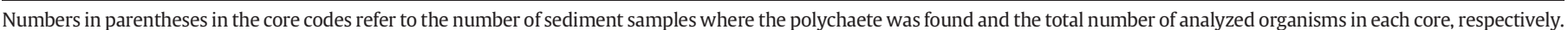

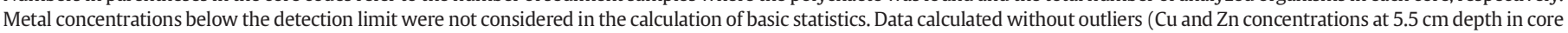
$1 \mathrm{E}$ for the $\mathrm{HCl}$ fraction, and $\mathrm{Cu}$ concentration at $14.5 \mathrm{~cm}$ in core $1 \mathrm{E}$ for the fraction). 
cores $2 \mathrm{E}, 3 \mathrm{E}, 5 \mathrm{E}$, and for $\mathrm{Zn}$ in all cores, with the highest BSAF value corresponding to site $5 \mathrm{E}$. These results suggest that $A$. brevis in Ensenada Harbor have a tendency to accumulate relatively more $\mathrm{Cu}$ and $\mathrm{Zn}$ compared to the other metals that we measured. The BSAF values for $\mathrm{Cd}, \mathrm{Co}, \mathrm{Ni}$ and $\mathrm{Pb}$ in this study were much lower than those previously reported for other species of polychaetes collected from China (Fan et al., 2014), India (Alam et al., 2010) and several UK estuaries (Casado-Martinez et al., 2009). The BSAF values for $\mathrm{Cu}$ and $\mathrm{Zn}$ observed in this study, however, were similar or even higher than those previously reported for other impacted sites (e.g., Alam et al., 2010: 0.53-1.29 for $\mathrm{Cu}$ and 0.95-2.93 for Zn; Fan et al., 2014: $0.19-0.77$ for $\mathrm{Cu}$ and $0.39-0.78$ for $\mathrm{Zn})$. These differences among regions are likely due in large part to behavioral and physiological differences among the various polychaete species used in these studies.

There was a strong correlation $\left(p \leq 0.01 ; r^{2}=0.87\right)$ between average reactive trace metal concentrations in sediments and metal concentrations in A. brevis (Fig. 11; note the logarithmic scales). Significant correlations were also calculated between metal concentrations in the polychaete and the total and $\mathrm{HCl}$ fractions $\left(p<0.05, r^{2}=0.75\right.$ and $p<0.05, r^{2}=0.72$, respectively). However, no significant correlations were observed between metal concentrations in the polychaete and those in the pyrite fraction. These relationships imply that the order of abundance of metals associated with the $\mathrm{HCl}$ fraction in the sediments influence the amounts of metals that are accumulated by the polychaete. However, metals associated with minerals that are stable under reducing conditions (e.g., pyrite and, maybe, AVS) appear to have no influence on metal bioaccumulation. Overall, our results suggest that the polychaete A. brevis accumulates trace metals from sediments and as such would be a good candidate for monitoring trace metal contamination in sediments.

\section{Conclusions}

Results from the analyses of the $\mathrm{HCl}$ and pyrite fractions showed that, generally, most metal concentrations were higher in sediments from Ensenada Harbor than those from El Sauzal Harbor, with significant differences $(p<0.05)$ found between the two harbors for all metals in both fractions (except for $\mathrm{Cd}$ and $\mathrm{Zn}$ in the $\mathrm{HCl}$ fraction). These results indicate that Ensenada Harbor sediments are, on average, more enriched

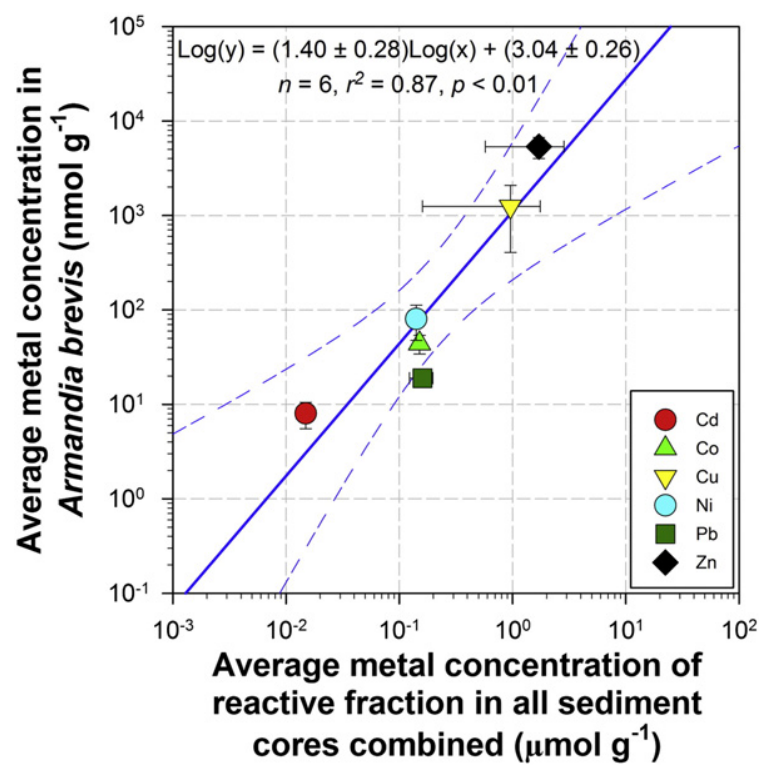

Fig. 11. Average metal concentrations accumulated in Armandia brevis plotted against average metal concentrations in the reactive fraction of the sediments from Ensenada Harbor. Data, calculated without outliers, represent mean \pm one standard deviation ( $\mathrm{n}=5$ for each metal). in trace metals, probably because this harbor is approximately 30 years older than El Sauzal and, therefore, has had more time to accumulate trace metals in the reactive fraction. Statistical analyses revealed significant differences $(p<0.05)$ between both fractions for all the metals measured in the two harbors, with the exception of Co in El Sauzal Harbor. The elevated number of correlations found among metals associated with the pyrite fraction suggests that this mineral phase plays an important geochemical role in the distribution of metals in the reduced sediments from both harbors.

Iron sulfide formation represents an important sink for Fe, with estimated fluxes of $\mathrm{Fe}^{2+}$ of $0.90 \mathrm{~mol} \mathrm{~m}^{-2} \mathrm{y}^{-1}$ towards the sediment in core $\mathrm{OE}$ (the only core for which dissolved Fe fluxes were measured). Our results indicate that $\mathrm{Fe}^{2+}$ fluxes of approximately the same magnitude converge in the middle portion of the core, which is the place where most of the solid Fe sulfides (pyrite and AVS) are actively forming and where $\mathrm{Fe}^{2+}$ fluxes approach values close to zero. Extrapolating the flux measured in the upper portion of the core to the whole of Ensenada Harbor, suggests that $98 \mathrm{mt}$ of Fe are precipitated as sulfides every year in the sediments of this harbor. This amount of Fe (and associated trace metals) will remain preserved in the sediments, until they are perturbed by dredging operations, sediment resuspension, or other physical means.

Based on the average composition of metals associated with the pyrite fraction, it is estimated that dredging will export to the open ocean considerable amounts of trace elements, with masses ranging from $0.20 \pm 0.13$ to $(0.30 \pm 0.56) \times 10^{3} \mathrm{mt}$ of $\mathrm{Cd}$ and $\mathrm{Cu}$, respectively (and even higher amounts of pyritic Fe), depending on the amounts of sediments dredged in each harbor. This trace element export represents a potential threat to marine benthic organisms, especially considering that pyrite (and associated trace metals) are unstable under oxic conditions, which are normally prevalent in the open ocean.

The extent of pyritization, as expressed by the DOP values, was relatively low while the extent of sulfidization (as expressed by the DOS) was high because of the elevated sedimentary AVS concentrations found in both harbors, with approximately $50 \%$ of the solid reactive Fe bound to sulfide. DOP values showed highly significant linear correlations with the DTMP ( $p \leq 0.001, n=254-256$ ), indicating that metals were being readily incorporated into pyrite as this mineral was formed. The order in which elements were increasingly pyritized in the sediments of both harbors was $\mathrm{Zn}<\mathrm{Pb}<\mathrm{Ni} \approx \mathrm{Cu}<\mathrm{Mn}<\mathrm{Cd}<\mathrm{Co}$, indicating that $\mathrm{Co}$ is the metal that is most readily pyritized. This incorporation of trace elements into the pyrite phase appears to be influenced by two main factors:

1) The magnitude of a given trace metal in the reactive fraction, as suggested by the very strong dependency $\left(p \leq 0.001, r^{2}=0.80, n=\right.$ 16) found between the average metal concentrations associated with the $\mathrm{HCl}$ fraction and those associated with the pyrite fraction in both harbors.

2) The solubility products of the different metal sulfides, as suggested by the significant correlations found between our average DTMP (and DOP) values (a proxy of solid sulfide activity) and the ratio $-\log \left(\mathrm{K}_{\mathrm{sp}(\mathrm{MeS})} / \mathrm{K}_{\mathrm{sp}(\mathrm{pyr})}\right)$ for both Ensenada $\left(p \leq 0.01, r^{2}=0.73\right.$, $n=8)$ and El Sauzal $\left(p \leq 0.05, r^{2}=0.57, n=8\right)$ Harbors.

The BSAF values of $\mathrm{Cd}, \mathrm{Co}, \mathrm{Ni}$ and $\mathrm{Pb}$ in the polychaete $\mathrm{A}$. brevis were lower than previously reported (e.g., Fan et al., 2014; Alam et al., 2010; Casado-Martinez et al., 2009) for other geographical locations (e.g., Jinzhou Bay in Nothern China, Sundarban mangrove wetland of India, and several UK estuaries, respectively); the BSAFs of $\mathrm{Cu}$ and $\mathrm{Zn}$, however, were higher in our harbors than those reported for these ecosystems. We found that the order of abundance of metals associated with the $\mathrm{HCl}$ fraction in the sediments influences the amounts of metals that are accumulated by the polychaete, as suggested by the highly significantly correlation $\left(p<0.01\right.$ and $\left.r^{2}=0.87\right)$ found between the average reactive trace metal concentrations and the metal concentrations measured in A. brevis. Most importantly, no significant correlation 
was observed between average metal concentrations in the pyrite fraction and those determined in the polychaete. These results imply that metals associated with the mineral phases present in, or originating from, the oxic part of the sediment influence the amounts of metals that are accumulated by the polychaete, whereas those present in the anoxic portion of the sediment do not have an appreciable effect on metal concentrations in A. brevis.

\section{Acknowledgments}

We are grateful to University of Cadiz for the "Contrato Puente para Doctores" given to Margarita Díaz-de-Alba. The author Margarita Díaz-de-Alba thanks Dr. Miguel Ángel Huerta-Diaz for his support during her postdoctoral stay at the Instituto de Investigaciones Oceanológicas (Universidad Autónoma de Baja California) in Mexico. Thanks to our late friend Rafael Blanco-Betancourt for his help during the diving and collection of the sediment cores from Ensenada Harbor and to Jenna and Nadine Hare for their help in the field and the laboratory. This study was funded by the State of Baja California and by the Consejo Nacional de Ciencia y Tecnología (Grant number SINVE001-EC). We would like to thank the anonymous reviewer that helped to improve this paper with his (her) constructive comments.

\section{Appendix A. Supplementary data}

Supplementary data associated with this article can be found in the online version, at http://dx.doi.org/10.1016/j.scitotenv.2015.11.033. These data include the Google map of the most important areas described in this article.

\section{References}

Alam, M.A., Gomes, A., Sarkar, S.K., Shuvaeva, O.V., Vishnevetskaya, N.S., Gustaytis, M.A. Bhattacharya, B.D., Godhantaraman, N., 2010. Trace metal bioaccumulation by soft-bottom polychaetes (Annelida) of Sundarban Mangrove Wetland, India and their potential use as contamination indicator. Bull. Environ. Contam. Toxicol. 85, 492-496

Alvarez-Borrego, J., Alvarez-Borrego, S., 1982. Temporal and spatial variability of temperature in two coastal lagoons. CalCOFI Reports 23, 188-198.

API, 1999. Programa maestro de desarrollo portuario de Ensenada, B.C. 2000-2005 Administración Portuaria Integral de Ensenada, S.A. de C.V., Resumen Ejecutivo, p. 30.

API, 2010. Manifestación de impacto ambiental modalidad regional para el "proyecto de desarrollo del puerto de El Sauzal, Baja California". Resumen Ejecutivo, Administración Portuaria Integral de Ensenada, S.A. de C.V., p. 27.

Berner, R.A., 1970. Sedimentary pyrite formation. Am. J. Sci. 268, 1-23.

Berner, R.A., 1980. Early Diagenesis. A Theoretical Approach. Princeton Series in Geochemistry. Princeton University Press, p. 241.

Bocchetti, R., Fattorini, D., Pisanelli, B., Macchia, S., Oliviero, L., Pilato, F., Pellegrini, D. Regoli, F., 2008. Contaminant accumulation and biomarker responses in caged mussels, Mytilus galloprovincialis, to evaluate bioavailability and toxicological effects of remobilized chemicals during dredging and disposal operations in harbor areas. Aquat Toxicol. 89, 257-266.

Boesen, C., Postma, D., 1988. Pyrite formation in anoxic environments of the Baltic. Amer. J. Sci. 288, 575-603.

Boudreau, B.P., 1996. The diffusive tortuosity of fine-grained unlithified sediments Geochim. Cosmochim. Acta 60, 3139-3142.

Burkhard, L., 2009. Estimation of biota sediment accumulation factor (BSAF) from paired observations of chemical concentrations in biota and sediment. U.S. Environmental Protection Agency, Ecological Risk Assessment Support Center, Cincinnati, OH EPA/ 600/R-06/047.

Carreón-Martínez, L.B., Huerta-Diaz, M.A., Nava-López, C., Siqueiros-Valencia, A., 2001 Mercury and silver concentrations in sediments from the Port of Ensenada, Baja California. Mexico. Mar. Pollut. Bull. 42, 415-418.

Casado-Martinez, M.C., Smith, B.D., DelValls, T.A., Luoma, S.N., Rainbow, P.S., 2009. Biodynamic modelling and the prediction of accumulated trace metal concentrations in the polychaete Arenicola marina. Environ. Pollut. 157, 2743-2750.

Chaudhuri, A., Mitra, M., Havrilla, C., Waguespack, Y., Schwarz, J., 2007. Heavy metal biomonitoring by seaweeds on the Delmarva Peninsula, east coast of the USA. Bot. Mar. 50, 151-158.

Chen, Z., Mayer, L.M., Quétel, C., Donard, O.F.X., Self, R.F.L., Jumars, P.A., Weston, D.P., 2000 High concentrations of complexed metals in the guts of deposit-feeders. Limnol. Oceanogr. 45, 1358-1367.

Cline, J.D., 1969. Spectrophotometric determination of hydrogen sulfide in natural waters Limnol. Oceanogr. 14, 454-458.

Cooper, D.C., Morse, J.W., 1996. The chemistry of Offatts Bayou, Texas: a seasonally highly sulfidic basin. Estuaries 19, 595-611.
Curiel-Ramírez, S., Cáceres-Martínez, J., 2010. Settlement of Mytilus galloprovincialis on collectors suspended at different depths in Bahía de Todos Santos B. C., Mexico. Aquaculture 300, 102-106.

Davies, S.H.R., Morgan, J.J., 1989. Manganese(II) oxidation kinetics on metal oxide surfaces. J. Colloid Interf. Sci. 129, 63-77.

Díaz-de-Alba, M., Galindo-Riaño, M.D., Casanueva-Marenco, M.J., Garcia-Vargas, M., Kosore, C.M., 2011. Assessment of the metal pollution, potential toxicity and speciation of sediment from Algeciras Bay (South of Spain) using chemometric tools. J. Hazard. Mater. 190, 177-187.

DiToro, D.M., Mahoney, J.D., Hansen, D.J., Scott, K.J., Hicks, M.B., Mayr, S.M., Redmond, M.S., 1990. Toxicity of cadmium in sediments: the role of acid volatile sulfide. Environ. Toxicol. Chem. 9, 1487-1502.

Eggleton, J., Thomas, K.V., 2004. A review of factors affecting the release and bioavailability of contaminants during sediment disturbance events. Environ. Int. 30, 973-980.

Fan, W., Xu, Z., Wang, W.-X., 2014. Metal pollution in a contaminated bay: relationship between metal geochemical fractionation in sediments and accumulation in a polychaete. Environ. Pollut. 191, 50-57.

Fathollahzadeh, H., Kaczala, F., Bhatnagar, A., Hogland, W., 2015. Significance of environmental dredging on metal mobility from contaminated sediments in the Oskarshamn Harbor, Sweden. Chemosphere 119, 445-451.

Flores-Rodríguez, J., Bussy, A.-L., Thevenot, D.R., 1994. Toxic metals in urban runoff: physico-chemical mobility assessment using speciation schemes. Wat. Sci. Tech. 29, $83-93$.

Flores-Vidal, X., Ramírez-Aguilar, I., Czitrom-Baus, S., 2005. Numerical simulation of the hydrodynamics of a port and effect of a wave-driven seawater pump. Cienc. Mar. 31, 57-77.

Gartman, A., Luther, G.W., 2014. Oxidation of synthesized sub-micron pyrite $\left(\mathrm{FeS}_{2}\right)$ in seawater Geochim. Cosmochim. Acta 144, 96-108.

Gibbs, M.M., 1979. A simple method for the rapid determination of iron in natural waters. Water Res. 13, 295-297.

Gonzalvez, A., Cervera, M.L., Armenta, S., de la Guardia, M., 2009. A review of nonchromatographic methods for speciation analysis. Anal. Chim. Acta 636, 129-157.

Hare, L., 1992. Aquatic insects and trace metals: bioavailability, bioaccumulation, and toxicity. CRC Cr. Rev. Toxicol. 22, 327-369.

Hatje, V. Apte, S.C., Hales, L.T., Birch, G.F., 2003. Dissolved trace metal distributions in Port Jackson estuary (Sydney Harbour). Australia. Mar. Pollut. Bull. 46, 719-730.

Howarth, R.W., 1978. A rapid and precise method for determining sulfate in seawater, estuarine waters, and sediment pore waters. Limnol. Oceanogr. 23, 1066-1069.

Huerta-Diaz, M.A., Morse, J.W., 1990. A quantitative method for determination of trace metal concentrations in sedimentary pyrite. Mar. Chem. 29, 119-144.

Huerta-Diaz, M.A., Morse, J.W., 1992. Pyritization of trace metals in anoxic marine sediments. Geochim. Cosmochim. Acta 56, 2681-2702.

Huerta-Diaz, M.A., Delgadillo-Hinojosa, F., Hernández-Ayón, M., Segovia-Zavala, J.A., García-Esquivel, Z., López-Zárate, H., Siqueiros-Valencia, A., Galindo-Bect, S., 2008. Diagnosis of trace metal contamination in sediments: the example of Ensenada and El Sauzal, two harbors in Baja California. Mexico. Mar. Environ. Res. $66,345-358$

Huerta-Diaz, M.A., Delgadillo-Hinojosa, F., Otero, X.L., Hernández-Ayón, J.M., Segovia-Zavala, J.A. Galindo-Bect MS Amaro-Franco, E, 2011. Iron and trace metals in microbial mats and underlying sediments: results from Guerrero Negro Saltern, Baja California Sur. México. Aquat. Geochem. 17, 603-628.

Huerta-Diaz, M.A., Muñoz-Barbosa, A., Otero, X.L., Valdivieso-Ojeda, J., Amaro-Franco, E.C., 2014. High variability in geochemical partitioning of iron, manganese and harmful trace metals in sediments of the mining port of Santa Rosalia, Baja California Sur. Mexico. J. Geochem. Explorat. 145, 51-63.

Jacobs, A., 1984. Metal geochemistry in anoxic marine basins Ph.D. Dissertation University of Washington, p. 234.

Laslett, R.E., Balls, P.W., 1995. The behaviour of dissolved Mn, Ni and $\mathrm{Zn}$ in the Forth, an industrialised, partially mixed estuary. Mar. Chem. 48, 311-328.

Li, Y.-H., Gregory, S., 1974. Diffusion of ions in sea water and in deep-sea sediments. Geochim. Cosmochim. Acta 38, 703-714.

Luoma, S.N., Rainbow, P.S., 2008. Metal Contamination in Aquatic Environments: Science and Lateral Management. Cambridge University Press, Cambridge, p. 588.

Machado, W., Rodrigues, A.P.C., Bidone, E.D., Sella, S.M., Santelli, R.E., 2011. Evaluation of $\mathrm{Cu}$ potential bioavailability changes upon coastal sediment resuspension: an example on how to improve the assessment of sediment dredging environmental risks. Environ. Sci. Pollut. R. 18, 1033-1036.

Martin, J.H., Broenkow, W.W., 1975. Cadmium in plankton: elevated concentrations off Baja California. Science 190, 884-885.

Martin, S., Proulx, I., Hare, L., 2008. Explaining metal concentrations in sympatric Chironomus species. Limnol. Oceanogr. 53, 411-419.

Meador, J.P., Rice, C.C., 2001. Impaired growth in the polychaete Armandia brevis exposed to tributyltin in sediment. Mar. Environ. Res. 51, 113-129.

Michaud, A.L., Hare, L., Campbell, P.G.C., 2005. Exchange rates of cadmium between a burrowing mayfly and its surroundings in nature. Limnol. Oceanogr. 50, 1707-1717.

Montero, N., Belzunce-Segarra, M.J., Del Campo, A., Garmendia, J.M., Ferrer, L., Larreta, J., González, M., Maidana, M.A., Espino, M., 2013. Integrative environmental assessment of the impact of Pasaia harbor activities on the Oiartzun Estuary. J. Mar. Syst. S252-S260.

Morgan, B., Rate, A.W., Burton, E.D., 2012. Water chemistry and nutrient release during the resuspension of FeS-rich sediments in a eutrophic estuarine system. Sci. Tot. Environ. 432, 47-56.

Muñoz-Arriola, F. 1994. Variabilidad de Cd, Cu y Pb en los aportes de aguas residuales del Arroyo El Gallo a la Bahía de Todos Santos durante el periodo mayo-diciembre de 1991 B.Sc. Thesis Universidad Autónoma de Baja California, p. 69. 
Muñoz-Barbosa, A., Gutiérrez-Galindo, E.A., Segovia-Zavala, J.A., Delgadillo-Hinojosa, F Sandoval-Salazar, G., 2004. Trace metal enrichment in surficial sediments of the northwest coast of Baja California. Mexico. Mar. Pollut. Bull. 48, 596-603.

Muñoz-Barbosa, A., Gutiérrez-Galindo, E.A., Daesslé, L.W., Orozco-Borbón, M.V., Segovia-Zavala, J.A., 2012. Relationship between metal enrichments and a biological adverse effects index in sediments from Todos Santos Bay, northwest coast of Baja California. México. Mar. Pollut. Bull. 64, 405-409.

Nava-López, C., 2002. Biogeoquímica de metales traza en sedimentos frente a la costa noroccidental de Baja California, México Ph.D. Dissertation Universidad Autónoma de Baja California, p. 179.

Nava-López, C., Huerta-Diaz, M.A., 2001. Degree of trace metal pyritization in sediments from the Pacific coast of Baja California. Mexico. Rev. Cienc. Mar. 27, 289-309.

Nayar, S., Miller, D.J., Hunt, A., Goh, B.P.L., Chou, L.M., 2007. Environmental effects of dredging on sediment nutrients, carbon and granulometry in a tropical estuary. Environ. Monit. Assess. 127, 1-13.

Naylor C., Davison W., Motelica-Heino M., van der Heijdt L.M. van den Berg G.A. (2012) Transient release of $\mathrm{Ni}, \mathrm{Mn}$ and Fe from mixed metal sulphides under oxidising and reducing conditions. Environ. Earth Sci. 65, 2139-2146.

Otero, X.L., Macias, F., 2003. Spatial variation in pyritization of trace metals in salt-marsh soils. Biogeochem. 62, 59-86.

Otero, X.L., Huerta-Diaz, M.A., Macias, F., 2003. Influence of a turbidite deposit on the extent of pyritization of iron, manganese and trace metals in sediments from the Guaymas Basin, Gulf of California (Mexico). Appl. Geochem. 18, 1149-1163.

Otero, X.L., Vidal-Torrado, P., Calvo de Anta, R.M., Macias, F., 2005. Trace elements in biodeposits and sediments from mussel culture in the Ría de Arousa (Galicia, NW Spain). Environ. Pollut. 136, 119-134.

Phillips, D.J.H., Rainbow, P.S., 1993. Biomonitoring of Trace Aquatic Contaminants. Springer, Netherlands, p. 371.

Rainbow, P.S., 2002. Trace metal concentrations in aquatic invertebrates: why and so what? Environ. Pollut. 120, 497-507.

Rickard, D., 2012. Sulfidic Sediments and Sedimentary Rocks. Elsevier, Amsterdam, p. 816.

Romero-Vargas-Márquez, I.P., 1995. Metales pesados y sus fracciones químicas en sedimentos de la Bahía de Todos Santos, Baja California, México M.Sc. Thesis Universidad Autónoma de Baja California, p. 86.
Sahuquillo, A., Rigol, A., Rauret, G., 2003. Overview of the use of leaching/extraction tests for risk assessment of trace metals in contaminated soils and sediments. TrAC-Trend. Anal. Chem. 22, 152-159.

Sañudo-Wilhelmy, S.A., Gill, G.A., 1999. Impact of the Clean Water Act on the levels of toxic metals in urban estuaries: the Hudson River Estuary revisited. Environ. Sci. Technol. 33, 3477-3481.

Sarkar, S.K., Favas, P.J.C., Rakshit, D., Satpathy, K.K., 2014. Geochemical speciation and risk assessment of heavy metals in soils and sediments. In: Hernandez Soriano, M.C. (Ed.), Environmental Risk Assessment of Soil Contamination. InTech - Open Access, pp. 723-757.

Schoonen, M., Elsetinow, A., Borda, M., Strongin, D., 2000. Effect of temperature and illumination on pyrite oxidation between $\mathrm{pH} 2$ and 6. Geochem. Trans. 1, 23-33.

Segovia-Zavala, J.A., Delgadillo-Hinojosa, F., Alvarez-Borrego, S., 1998. Cadmium in the coastal upwelling area adjacent to the California-Mexico Border. Estuar. Coast. Shelf Sci. 46, 475-481.

Stookey, L.L., 1970. Ferrozine - new spectrophotometric reagent for iron. Anal. Chem. 42 779-781.

Stumm, W., Morgan, J.J., 1996. Aquatic Chemistry, Chemical Equilibria and Rates in Natural Waters. John Wiley \& Sons, New York, p. 1022.

Usero, J., González-Regalado, E., Gracia, I., 1996. Trace metals in the bivalve mollusc Chamelea gallina from the Atlantic Coast of Southern Spain. Mar. Pollut. Bull. 32 305-310.

Usero, J., González-Regalado, E., Gracia, I., 1997. Trace metals in the bivalve molluscs Ruditapes decussatus and Ruditapes philippinarum from the Atlantic coast of Southern Spain. Environ. Int. 23, 291-298.

Usero, J., Morillo, J., Gracia, I., 2005. Heavy metal concentrations in molluscs from the Atlantic coast of southern Spain. Chemosphere 59, 1175-1181.

Varol, M., 2011. Assessment of heavy metal contamination in sediments of the Tigris river (Turkey) using pollution indices and multivariate statistical techniques. J. Hazard. Mater. 195, 355-364

Wang, W.X., Stupakoff, I., Fisher, N.S., 1999. Bioavailability of dissolved and sediment-bound metals to a marine deposit-feeding polychaete. Mar. Ecol. Prog. Ser. 178, 281-293.

Yeats, P.A., Bewers, J.M., 1985. Manganese in the western North Atlantic Ocean. Mar. Chem. 17, 255-263. 